\title{
Efectos de la tectónica y el clima en la configuración morfológica del relieve costero del norte de Chile
}

\author{
Jorge Quezada ${ }^{1}$, José Luis Cerda ${ }^{2}$, Arturo Jensen ${ }^{2}$
}

\author{
l' Departamento de Ciencias de la Tierra, Universidad de Concepción, Casilla 160-C, Concepción, Chile. Programa de Doctorado \\ en Ciencias, mención Geología, Universidad Católica del Norte, Departamento Ciencias de la Tierra. \\ jquezad@udec.cl \\ 2 Departamento de Ciencias Geológicas, Universidad Católica del Norte, Casilla 1280, Antofagasta, Chile. \\ cerda@ucn.cl;jensen@ucn.cl
}

\begin{abstract}
RESUMEN. En este trabajo se analiza el relieve de la vertiente occidental de la Cordillera de la Costa del norte de Chile, la cual está caracterizada por la ocurrencia del gran Acantilado Costero. El objetivo central de este estudio es establecer los controles tectónico-climáticos en la configuración del relieve del borde costero del norte de Chile. La metodología utilizada consiste básicamente en un estudio detallado del relieve mediante índices geomorfológicos cuantitativos tales como grado de incisión, curvas e integrales hipsométricas, perfiles de thalweg e índice de sinuosidad. Estos índices se aplicaron a modelos de elevación digitales e imágenes satelitales. Los resultados más relevantes muestran que el relieve de la vertiente occidental de la Cordillera de la Costa exhibe creciente incremento de la intensidad de la erosión al aumentar la latitud. Este incremento no es uniforme; procesos relacionados con la tectónica como subsidencia/alzamiento litoral y actividad de fallas, y por otra parte la erosión de la paleotopografía de la Cordillera de la Costa debido a los procesos ligados a la construcción del Acantilado Costero y el aumento de la precipitación, afectan la morfología del relieve del borde costero del norte de Chile. La existencia y excelente preservación del Acantilado Costero resulta de un marcado desequilibrio entre las tasas de alzamiento y las tasas de erosión, cuya diferencia es de una a dos órdenes de magnitud, controlada por el marco climático de hiperaridez extrema del Desierto de Atacama que se ha mantenido por lo menos desde los últimos $2 \mathrm{Ma}$. Las variaciones en la intensidad de la erosión desde el norte hacia el sur se interpretan como resultado del incremento en la tasa de precipitación en un orden de magnitud en esa misma dirección.
\end{abstract}

Palabras clave: Geomorfología, Norte de Chile, Acantilado Costero, Tectónica, Clima.

\begin{abstract}
Tectonic and climatic effects in the morphologic configuration of the coastal relief of northern Chile. This work analyzes the morphological features of the western margin of the northern Chile Coastal Cordillera, characterized by the presence of a major Coastal Cliff. The main purpose of this research is to better understand the tectonic and climatic controls on the topography. The methodology used consists basically of a detailed study of the topography with quantitative geomorphic indexes such as incision grade, hypsometric curves and integrals, thalweg profiles and sinuosity index. These are applied to digital elevation models and satellite images. The main results show that the topography of the western margin of the Coastal Cordillera, exhibits an increasing intensity of the erosion with latitude. This increment is non uniform. The tectonic processes that produced coastal subsidence/uplift and fault activity, and the erosion of the paleotopography of Coastal Cordillera due to processes related with the construction of the Coastal Cliff and increasing rainfall, modify the morphology of the coastal border of northern Chile. The existence and conservation of the Coastal Cliff results from the existance of non-equilibrium between the uplift and erosion rates. Both rates have one-two order magnitude difference, controlled by the extreme hyperarid climate of the Atacama Desert. These conditions prevailed at least for the last $2 \mathrm{~m}$.yrs. The variations in the intensity of the erosion from north to south are interpreted as the result of the southward increase in precipitacion by one order of magnitude.
\end{abstract}




\section{Introducción}

El relieve del borde costero del norte de Chile está dominado por la existencia de un gran Acantilado Costero que limita por el oeste a la Cordillera de la Costa. Este rasgo fisiográfico se extiende por más de $1.000 \mathrm{~km}$ entre los $18,5^{\circ}$ hasta $29^{\circ} \mathrm{S}$ por lo menos y alcanza altitudes de hasta 2.000 m s.n.m., constituyendo una singularidad morfológica en la región circumpacífica. Si se considera que gran parte de esta región corresponde a una zona de subducción activa, esta última no constituye por sí sola el factor que explica la presencia del gran Acantilado Costero. En este sentido, las condiciones climáticas de extrema aridez que imperan juegan un papel relevante; en efecto, el gran Acantilado Costero se restringe al Desierto de Atacama, porción más árida del margen circumpacífico. Dado que las condiciones de extrema aridez del Desierto de Atacama han permitido la preservación de superficies tan antiguas como Oligoceno-Mioceno en la Cordillera de la Costa (Dunai et al., 2005), resulta natural considerar que su origen se debe a una interacción entre procesos endógenos vinculados a la subducción, y procesos exógenos asociados a un régimen climático de aridez, que han sido poco eficientes en la degradación del relieve.

El gran Acantilado Costero presenta segmentos activos donde la abrasión marina afecta la erosión del talud y segmentos inactivos donde en su base existe una plataforma de abrasión marina emergida. En los segmentos inactivos el talud está solamente afectado por procesos de erosión subaéreos ligados al clima, que se evidencian por el desarrollo o ausencia de redes de drenaje que descienden por el talud. Estas variaciones morfológicas latitudinales del Acantilado Costero permiten ponderar en el origen y evolución de este relieve: el efecto de la tectónica (alzamiento/subsidencia litoral regional y sistemas de fallas presentes en la Cordillera de la Costa), y del clima (variaciones latitudinales del grado de aridez/tasas de precipitación).

Debido a estas variaciones latitudinales, en el presente estudio se intenta diferenciar la impronta en el relieve del gran Acantilado Costero asociada a este régimen de aridez extrema, de aquella asociada a la tectónica para lo cual se consideró el análisis de índices geomorfológicos cuantitativos que ponderan los efectos del clima y la tectónica en la evolución del relieve, como el índice de sinuosidad, curva hipsométrica, perfiles de thalweg y grado de incisión. Estos índices se obtienen mediante un modelo de elevación digital de terreno SRTM 90 (USGS) e imágenes Landsat (resolución espacial $15 \mathrm{~m}$ ) del relieve del borde costero del norte de Chile entre $\operatorname{los} 18,5^{\circ}$ y $27,5^{\circ} \mathrm{S}$. Sobre la base de estos índices ha sido posible determinar variaciones latitudinales de la morfología del Acantilado Costero, las cuales se discuten y se relacionan con variaciones tectónicas, climáticas y paleoclimáticas dentro de un marco climático caracterizado por una aridez extrema.

Acerca del origen del Acantilado Costero, se han planteado hipótesis variadas y contrastantes no existiendo consenso científico ni conclusiones determinantes. Brüggen (1950), Armijo y Thiele (1990) postulan que el Acantilado Costero es un escarpe de falla; Paskoff (1979) establece que es un escarpe de falla que ha retrocedido producto de la abrasión marina; Mortimer y Saric $(1972,1975)$ proponen que el Acantilado Costero es un relieve netamente erosivo generado durante una subsidencia litoral, en cambio Hartley y Jolley (1995), plantean que este relieve se generó en un litoral que experimenta alzamiento tectónico. Todas estas hipótesis consideran el factor tectónico como preponderante para su existencia. El presente trabajo pretende también precisar el origen del Acantilado Costero, lo cual es importante para comprender su evolución.

\section{Marco fisiográfico}

El relieve del norte de Chile forma parte de los Andes Centrales y se caracteriza por la presencia de cuatro unidades fisiográficas longitudinales principales que, de oeste a este son: Cordillera de la Costa, Depresión Intermedia, Precordillera y Cordillera Occidental (Fig. 1). El relieve costero está dominado por la presencia de la Cordillera de la Costa que presenta un ancho de $20-40 \mathrm{~km}$ y alturas medias del orden de 1.500-2.000 m s.n.m., alcanzando un máximo en la Sierra Vicuña Mackenna $\left(24,5^{\circ} \mathrm{S}\right.$, con 3.100 m s.n.m.). El límite entre la Cordillera de la Costa y la Depresión Intermedia es difuso y ocurre aproximadamente a la cota de $1.000 \mathrm{~m}$. En cambio, la vertiente occidental está formada por el gran Acantilado Costero que limita a dicha cordillera con el Océano Pacífico. A lo largo de toda su extensión, el Acantilado Costero presenta segmentos activos e inactivos. Los segmentos activos se localizan entre Arica e Iquique $\left(18,5^{\circ}-20,3^{\circ} \mathrm{S}\right)$ y entre Caleta Coloso 
y Caleta El Cobre $\left(24^{\circ}-24,5^{\circ} \mathrm{S}\right)$. En estos segmentos el acantilado se encuentra directamente expuesto a la abrasión marina y el socavamiento genera pendientes fuertes que superan los $45^{\circ}$ y el talud está constituido por roca. En los segmentos inactivos, el Acantilado Costero se encuentra separado de la línea de costa por una estrecha plataforma de abrasión marina emergida, labrada al pie del Acantilado Costero. Estos segmentos se localizan entre Iquique y Antofagasta $\left(20,3^{\circ}-23,5^{\circ} \mathrm{S}\right)$ y al sur de la Caleta El Cobre $\left(24,5^{\circ} S\right)$. Para los fines del presente estudio se considera el límite sur la desembocadura del río Copiapó $\left(27,5^{\circ} \mathrm{S}\right)$. A lo largo de los segmentos inactivos, el Acantilado Costero se caracteriza por el desarrollo de un prominente talud de detritos cuya pendiente de equilibrio es del orden de $30^{\circ}$. El talud también posee campos de dunas que pueden alcanzar las cotas medias de elevación del acantilado. Al sur de los $21,7^{\circ} \mathrm{S}$, el talud es atravesado por numerosas quebradas en cuya base se desarrollan abanicos aluviales que se depositan sobre la plataforma de abrasión marina emergida.
Esta plataforma se extiende desde la línea de costa hasta una altura máxima de $200 \mathrm{~m}$ s.n.m. y está formada por varias terrazas marinas escalonadas. La edad de la terraza más alta ha sido asignada al Plioceno por Martínez y Niemeyer (1982), en tanto que Marquardt et al. (2005) le asignaron una edad mínima de 2,61 $\pm 0,14$ Ma sobre la base de la datación $\mathrm{Ar} / \mathrm{Ar}$ de un horizonte de ceniza que cubre esta terraza en la Punta Yayes $\left(22,8^{\circ} \mathrm{S}\right)$. Quezada et al. (2007) establecieron una edad de $0,86 \pm 0,11 \mathrm{Ma}$ en el área de Caldera utilizando ${ }^{21} \mathrm{Ne}$ cosmogénico en los depósitos que cubren la terraza más alta. En cotas inferiores de esta plataforma se desarrollan terrazas marinas más jóvenes, cuyas edades son menores a los $500 \mathrm{ka}$ (Leonard y Wehmiller, 1991; Ortlieb et al., 1996 y Delouis et al., 1998). Sobre la base de las edades de las terrazas marinas, su altura y la posición del nivel del mar en el momento de su formación, se han determinado tasas de alzamiento litoral que fluctúan entre 0,06-0,34 mm/a (Leonard y Wehmiller, 1991; Ortlieb et al., 1994; Martínez y Niemeyer, 1982; Marquardt et al., 2004, Quezada et al., 2007).
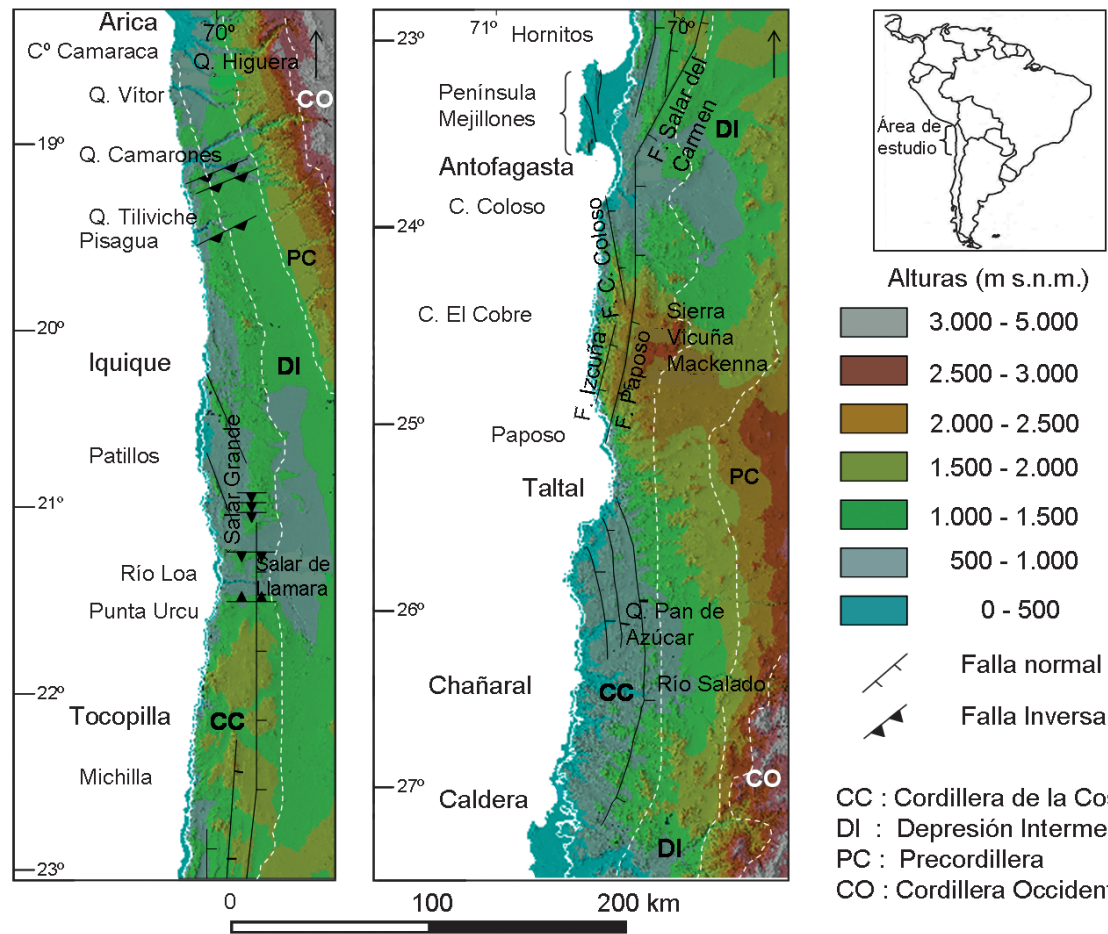

CC : Cordillera de la Costa

$\mathrm{DI}$ : Depresión Intermedia

PC : Precordillera

CO : Cordillera Occidental

FIG. 1. Área de estudio. Se indican las unidades del relieve y sistemas de fallas principales en la Cordillera de la Costa. En la línea llena blanca, el trazado de la base del Acantilado Costero. Línea segmentada señala bordes de unidades fisiográficas CC, DI, $\mathrm{PC}$ y CO. 


\section{Marco climático}

El territorio del norte de Chile, entre $\operatorname{los} 18,5^{\circ} \mathrm{y}$ $28^{\circ} \mathrm{S}$, se encuentra enmarcado dentro del Desierto de Atacama que presenta condiciones de aridez extrema, caracterizada por pluviosidades inferiores a $30 \mathrm{~mm} / \mathrm{a}$ en la Depresión Intermedia y Cordillera de la Costa (Houston y Hartley, 2003; Dirección Meteorológica de Chile, 2005). Al norte de los $24^{\circ} \mathrm{S}$, las precipitaciones son inferiores a $5 \mathrm{~mm} / \mathrm{a}$ (Tabla 1). La temperatura media anual es del orden de $18^{\circ} \mathrm{C}$ y las amplitudes térmicas del orden de $6-7^{\circ} \mathrm{C}$ en el litoral y $25^{\circ} \mathrm{C}$ al interior (Dirección Meteorológica de Chile, 2005). Las tasas de precipitaciones extremadamente bajas en el Desierto de Atacama, se deben principalmente a la presencia del anticiclón del Pacífico que frena y desvía los sistemas frontales desde el sur, y la presencia del macizo andino por el este, que con alturas del orden de 5.000-6.000 $\mathrm{m}$ s.n.m., forma una barrera para las masas de aire húmedo de la vertiente amazónica de los Andes (Ortlieb, 1995; Vargas y Ortlieb, 1998; Houston y Hartley, 2003). La presencia de la corriente fría de Humbolt acentúa aún más las bajas precipitaciones debido al enfriamiento de las masas de agua oceánicas (Hartley, 2003).

Las bajas precipitaciones imponen un régimen de hiperaridez en el Desierto de Atacama. No obstante, en este desierto se desarrollan lluvias torrenciales de alta intensidad y corta duración que pueden producirse por tres procesos fundamentales: i. Precipitaciones estacionales debido a la propagación hacia el norte de los sistemas frontales provenientes desde el SO. ii. Precipitaciones periódicas originadas por el fenómeno de El Niño que consiste en un calentamiento de la temperatura del Océano Pacífico y el debilitamiento del anticiclón del Pacífico. El fenómeno El Niño se manifiesta aproximadamente cada 10 años (Vargas et al., 2007) y provoca un aumento de la frecuencia e intensidad de sistemas frontales y sus incursiones hacia el norte. Las lluvias pueden ser intensas, como las que ocurrieron en 1991 en Antofagasta donde las precipitaciones alcanzaron una intensidad entre 14 y $42 \mathrm{~mm} / \mathrm{h}$ (Vargas et al., 2000). iii. Precipitaciones debidas a núcleos fríos en altura o bajas segregadas que pueden afectar el litoral del norte de Chile $\left(18,5^{\circ}-30^{\circ} \mathrm{S}\right)$. Durante estos eventos, se desarrolla principalmente nubosidad de tipo alto-cúmulos-nimbos que en algunos casos se propaga desde el NO hacia el SE y provocan
TABLA 1. PRECIPITACIONES EN DISTINTAS LOCALIDADES DEL LITORAL DEL NORTE DE CHILE DURANTE UN REGISTRO DE 30 AÑOS.*

\begin{tabular}{llc}
\hline \multicolumn{1}{c}{ Localidad } & $\begin{array}{c}\text { Latitud } \\
\left({ }^{\circ} \mathbf{S}\right)\end{array}$ & $\begin{array}{c}\text { Precipitación } \\
(\mathbf{m m} / \mathbf{a n ̃ o})\end{array}$ \\
\hline Arica & 18,5 & 0,5 \\
Iquique & 20,8 & 0,6 \\
Tocopilla & 22 & 2 \\
Antofagasta & 23,5 & 1,7 \\
Taltal & 24,4 & 8 \\
Chañaral & 26,2 & 12 \\
Caldera & 27 & 27 \\
La Serena & 29,9 & 78 \\
Tangue & 30,3 & 107 \\
Puerto Oscuro & 31,4 & 163 \\
\hline
\end{tabular}

* Dirección Meteorológica de Chile, 2005.

precipitaciones que pueden llegar a los $10 \mathrm{~mm} /$ día (Quezada, 2006). Estos fenómenos históricamente no han sido documentados mediante estudios sistemáticos; sin embargo, eventos de este tipo se han manifestado entre los años 2002 y 2006, generando aluviones significativos en el Acantilado Costero, los principales entre $22^{\circ}-23^{\circ} \mathrm{S}$ y $25^{\circ}-25,5^{\circ} \mathrm{S}$.

Si bien existe consenso en que las condiciones de aridez imperantes en el Desierto de Atacama son muy antiguas, la edad propuesta para el establecimiento de esta aridez por los diferentes autores difiere, dependiendo de los objetos geológicos estudiados y de las escalas de tiempo y espacio consideradas. Sobre la base de las características de las facies sedimentarias de las unidades mesozoicas y cenozoicas expuestas entre la Cordillera de la Costa y la Precordillera del Desierto de Atacama, Hartley et al. (2005) sugieren que las condiciones de aridez en la región serían tan antiguas como Jurásico Superior. Edades de exposición ${ }^{21} \mathrm{Ne}$ de clastos sobre peniplanicies permiten a Dunai et al. (2005) sugerir que la hiperaridez está presente en la Cordillera de la Costa al menos desde el Oligoceno. Por su parte, Alpers y Brimball (1988) consideran edades de alteración supérgena en la Precordillera y proponen un período de menor aridez con anterioridad a los $14 \mathrm{Ma}$, que precede al establecimiento de la hiperaridez. En la Depresión Intermedia, estudios que consideran la evolución depositacional de la Cuenca Calama $\left(\sim 23^{\circ} \mathrm{S}\right)$, inducen a Hartley y Chong (2002) a proponer que las condiciones de aridez imperaban ya en el Desierto de Atacama a los $\sim 6 \mathrm{Ma}$, y que el establecimiento definitivo de las actuales condicio- 
nes de hiperaridez se produce solo en el Plioceno a $~ 3$ Ma. Durante las glaciaciones pleistocenas, Vargas y Ortlieb (1998) señalaron que ocurrieron lluvias más frecuentes durante episodios glaciales o tardiglaciales, particularmente con posterioridad al interglaciar ocurrido hace $125 \mathrm{ka}$ en la costa del área de Antofagasta. Estos autores plantearon que el clima de hiperaridez actual en la región costera se desarrolló sólo a partir del Holoceno temprano.

Las condiciones de aridez que han imperado en el Desierto de Atacama durante el Cenozoico tardío han permitido la preservación de superficies tan antiguas como Oligoceno-Mioceno en la Cordillera de la Costa del extremo norte de Chile (Dunai et al., 2005). Asimismo, estas condiciones han favorecido bajas tasas de erosión en la región de antearco, con valores que disminuyen desde $0,02 \mathrm{~mm} / \mathrm{a}$, en la Precordillera, a $0,002 \mathrm{~mm} /$ año en la Cordillera de la Costa (Kober, et al., 2002; Riquelme et al., 2008).

\section{Marco geológico}

El borde occidental de la Cordillera de la Costa, entre los $18,5^{\circ}-25^{\circ} \mathrm{S}$, está compuesto principalmente por rocas andesíticas, remanentes de un antiguo arco magmático jurásico (Salas et al., 1966; Cecioni y García, 1960; García, 1967). Al sur de los $25^{\circ} \mathrm{S}$ y hasta los $27,5^{\circ} \mathrm{S}$, este arco magmático está representado principalmente por granodioritas, gabros y monzogranitos que intruyeron un complejo epimetamórfico paleozoico (Godoy et al., 2003). Los depósitos cenozoicos más antiguos en la Cordillera de la Costa corresponden a gravas que se presentan al interior de la Cordillera de la Costa y que se encuentran expuestos en la parte alta del Acantilado Costero. Dataciones en cenizas volcánicas intercaladas en estos depósitos arrojan una edad oligoceno-miocena (Naranjo y Paskoff, 1985). En la base del Acantilado Costero se encuentran rocas del Mioceno Superior-Plioceno, formadas por areniscas, areniscas coquinoideas y lutitas que yacen horizontales y representan un ambiente marino. Sobre estas rocas existen depósitos pleistocenos aterrazados que se formaron en un ambiente litoral (Martínez y Niemeyer, 1982; Ortlieb et al., 1994; Ortlieb et al., 1996; Marquardt et al., 2004 y Quezada et al., 2007).

En la Cordillera de la Costa del norte de Chile, existen tres sistemas estructurales importantes: un sistema de fallas de orientación norte-sur que con- forman el Sistema de Falla de Atacama (Arabasz, 1971), un sistema de fallas inversas de orientación este-oeste (Allmendinger et al., 2005) y un sistema de fallas de orientación NNO-SSO, principalmente con movimiento de rumbo dextral (González et al., 2003; Carrizo et al., 2008a, b) (Fig. 1).

El principal sistema estructural de la Cordillera de la Costa del norte de Chile corresponde al sistema de fallas de orientación norte-sur que conforma el Sistema de Falla de Atacama (SFA). El movimiento del SFA fue de rumbo en el Mesozoico y predominantemente vertical, con bloque alzado ubicado al oeste de las trazas, durante el Cenozoico que indica una extensión aproximadamente E-O (Arabasz, 1971; Okada, 1971; Mortimer, 1980; Hervé, 1987; Armijo y Thiele, 1990; Scheuber y Andriessen, 1999; Riquelme et al., 2003). Este sistema se extiende aproximadamente desde los $20^{\circ} \mathrm{S}$ hasta los $28^{\circ} \mathrm{S}$, y está formado por numerosas fallas de manteo subvertical, que definen tres segmentos principales (Salar del Carmen, Paposo y Salado), los que vistos en planta tienen morfología cóncava al oeste y limitan una topografía más alta al oeste de las trazas. El segmento Salar del Carmen $\left(\sim 20^{\circ}-\right.$ $\left.23,6^{\circ} \mathrm{S}\right)$ está dominado por la Falla Salar del Carmen (Fig. 1) que conforma la traza más oriental de este segmento. La zona sur de esta falla constituye un frente de montaña con control tectónico donde existe un bloque solevantado de la Cordillera de la Costa situado al oeste de la traza (González et al., 2006). En el extremo sur de este segmento, existen numerosas trazas de fallas de rumbo $\sim \mathrm{N}-\mathrm{S}$ al oeste de la Falla Salar del Carmen. Esta zona coincide con la presencia de la península de Mejillones como rasgo topográfico situado al oeste de la Cordillera de la Costa (Fig. 1) donde también existen fallas normales de orientación norte-sur. El número de trazas de falla disminuye progresivamente hacia el norte de este segmento y éstas se extienden por el interior de la Cordillera de la Costa sin constituir un frente de montaña propiamente tal pero limitan serranías. Al norte del río Loa, las trazas son difíciles de distinguir. El segmento Paposo $\left(23,6^{\circ}-25^{\circ} \mathrm{S}\right)$ está dominado por las fallas Paposo, Izcuña y Caleta Coloso (Fig. 1) (e.g., Hervé, 1987; Cembrano et al., 2005). Existe un número menor de fallas en que las mencionadas son las principales y se caracterizan por tener escarpes erosionados de gran altura en que el mayor es el de la falla Paposo que alcanza los $200 \mathrm{~m}$. Entre los $25^{\circ}-25,5^{\circ} \mathrm{S}$ (Paposo-Taltal), no se 
presenta el SFA y el segmento Salado se extiende desde los $25,5^{\circ} \mathrm{S}$ hasta los $27^{\circ} \mathrm{S}$ por lo menos, siendo el límite sur difuso. Este segmento se caracteriza por la presencia de numerosas trazas subparalelas, y a diferencia de los segmentos anteriores, los escarpes son discontinuos debido a numerosos drenajes que provienen de la Precordillera que los atraviesan, llegando hasta el mar o a depresiones intramontanas. Los escarpes de las fallas más orientales de los segmentos Salar del Carmen y Paposo, constituyen barreras topográficas a los drenajes que provienen desde la Precordillera.

El sistema de fallas inversas de orientación este-oeste se extiende desde la quebrada Camarones $\left(19^{\circ} \mathrm{S}\right)$ hasta el sur del río Loa $\left(21,6^{\circ} \mathrm{S}\right)$ (Allmendinger et al., 2005; González et al., 2003; Carrizo et al., 2008a, b). Estas fallas se restringen exclusivamente a la Cordillera de la Costa y están compuestas por varias trazas paralelas y los escarpes condicionan un conspicuo control del relieve. Estos escarpes tienen una pendiente hacia el norte o sur con un predominio hacia el norte. Normalmente, la superficie del los bloques de techo de estas fallas poseen una topografía antiforme, que corresponde a la expresión superficial de un pliegue asociado a la propagación de las fallas en profundidad. Las superficies antiformes ( $>5 \mathrm{~km}$ de longitud de onda) y los escarpes más notorios (hasta $150 \mathrm{~m}$ de altitud) corresponden a los sistemas de falla Chuculay, Pisagua y Atajaña (Allmendinger et al., 2005; González et al., 2003 y Carrizo et al., 2008a, b). En la plataforma de abrasión marina emergida en la base del Acantilado Costero, se reconocen también escarpes de falla y superficies antiformes al sur de Iquique en el sector de Barranco Alto (Allmendinger et al., 2005), al norte y sur del río Loa, y en la zona de Pisagua (Fig. 1). En todas estas zonas, estas superficies antiformes contribuyen al alzamiento local de la plataforma de abrasión marina, la que presenta una altura y ancho mayor.

El sistema de fallas de orientación NNO-SSE se desarrolla entre Iquique y el Salar Grande $\left(20^{\circ}\right.$ $21^{\circ} \mathrm{S}$ ). En la zona del Salar Grande estas fallas son del tipo dextral-inverso con actividad durante el Mioceno y Plioceno (Carrizo et al., 2008a). La mayoría de los escarpes de estas fallas tienen una pendiente hacia el este y constituyen frentes de montañas, algunos de ellos invertidos (Carrizo et al., 2008a). Este frente montañoso se localiza al SO de los escarpes.
Las trazas de las fallas inversas de orientación E-O atraviesan las trazas del SFA y del sistema NNO-SSE lo que indica que son las estructuras más jóvenes. El talud del Acantilado Costero corta las trazas de los tres sistemas descritos indicando que los procesos de erosión más recientes que afectan al Acantilado Costero, son posteriores a la actividad de las fallas. No obstante lo anterior, la actividad de estas fallas generando desniveles topográficos, puede condicionar la erosión del Acantilado Costero y su segmentación longitudinal. Actividad más reciente de algunas fallas inversas E-O se evidencia en la plataforma de abrasión marina emergida en la base del Acantilado Costero, provocando desniveles locales y basculamientos. De este modo la actividad de algunas de estas fallas ocurrió antes, durante y después de la formación del Acantilado Costero.

Producto de la convergencia de las placas de Nazca y Sudamericana, se generan terremotos de subducción que han afectado el litoral del norte de Chile produciéndose episodios de alzamiento y subsidencia durante la ocurrencia del sismo (período cosísmico). Se han reportado alzamientos cosísmicos en el litoral entre Tocopilla y Taltal $\left(22^{\circ}-25^{\circ} \mathrm{S}\right)$ durante los terremotos de Antofagasta 1995 y Tocopilla 2007 (Ruegg et al., 1996; Klotz et al., 1999; Béjar-Pizarro et al., 2008) y subsidencia cosísmica entre Arica e Iquique $\left(18,5^{\circ}-20,3^{\circ} \mathrm{S}\right)$ durante los terremotos de Arica de 1868 y 1877 (Kausel, 1986). Quezada et al. (2005) encontraron una relación entre la zona de subsidencia cosísmica y la presencia del Acantilado Costero activo al norte de Iquique y alzamiento cosísmico y Acantilado Costero inactivo por alzamiento de la plataforma de abrasión marina al sur de Iquique. Este cambio de régimen entre alzamiento y subsidencia cosísmica se debe al hecho de que la distancia litoral-fosa aumenta progresivamente al norte de Iquique y esta distancia es la que condiciona la zona entre alzamiento cosísmico y subsidencia cosísmica. De esta forma, la presencia de un Acantilado Costero activo al norte de Iquique puede ser explicada por la ocurrencia de terremotos de subducción al estar en una zona de subsidencia cosísmica.

\section{Análisis geomorfológico cuantitativo}

La Geomorfología Tectónica estudia la relación entre los procesos tectónicos (endógenos) que tienden a construir un relieve y los procesos superficiales 
(exógenos) que tienden a disminuir las elevaciones. Además, se ocupa de la definición de este balance y la interpretación del paisaje que resulta (Burbank y Anderson, 2001). Los procesos endógenos y exógenos, en general, no son constantes ni actúan con la misma intensidad durante el tiempo. Existen tres modelos que explican la evolución del relieve. 1. El modelo de Davis (Davis, 1899) considera que los procesos endógenos solo constituyeron un pulso inicial que generó el alzamiento de las rocas contribuyendo a elevar las alturas y después solo actuaron los procesos exógenos que contribuyeron al modelado del relieve, disminuyendo las alturas y de formas con poco contraste. 2. El modelo de Penck (Penck, 1953) considera que la deformación tectónica es continua, pero con intensidad variable, alcanzando un valor máximo para después disminuir. La erosión comienza a actuar cuando se alza el relieve y como el solevantamiento disminuye al final, prevalece la erosión y causa una reducción parcial de la topografía residual. 3. El modelo de Hack (Hack, 1975), establece que una vez que la razón entre la tasa de deformación y la tasa de erosión es constante durante un largo intervalo de tiempo, el paisaje entra en un equilibrio dinámico: las tasas de alzamiento de las rocas y erosión están equilibradas de modo que el alzamiento de superficie no presenta variaciones (Alzamiento de superficie=alzamiento de roca-exhumación, Molnar y England, 1990). Aún no existe consenso sobre cuál de los tres modelos explica la evolución de los relieves actuales y es más factible considerar que, dado un contexto regional en que exista una evolución tectónica y climática determinada, se pueda aplicar alguno de ellos.

La utilidad de índices morfométricos para la determinación de la evolución de los relieves considerando el balance entre la componente tectónica y climática, ha sido expuesta por Keller y Pinter (1996) y sobre la base de los ejemplos allí indicados es que se considera apropiado utilizar algunos de esos índices para el área de estudio. De este modo, la caracterización morfométrica del relieve del borde costero del norte de Chile se realizó mediante cuatro índices fundamentales que son: i. grado de incisión de la topografía de la Cordillera de la Costa; ii. determinación de curvas e integrales hipsométricas de los sistemas de drenajes que afectan al Acantilado Costero; iii. estudio de los perfiles de thalweg de estos drenajes y iv. el índice de sinuosidad de la base del Acantilado Costero. La información combinada de estos índices permite resaltar las variaciones morfológicas latitudinales de la Cordillera de la Costa y particularmente, del Acantilado Costero, precisando su origen y evolución e identificando la influencia relativa de la tectónica y clima.

\subsection{Grado de incisión}

Dentro del proceso de generación de relieves, existe una etapa inicial en que se desarrollan incisiones profundas en el relieve, que posteriormente se ensanchan y los drenajes adquieren mayor desarrollo, provocando que los rasgos originales del relieve se vayan degradando debido a la mayor erosión. De tal forma, el grado de incisión es un reflejo del estadio de evolución de un relieve. Se considerarán dos enfoques para caracterizar el grado de incisión en el relieve costero del norte de Chile: perfiles topográficos de orientación meridiana en la Cordillera de la Costa, y variaciones latitudinales de altitud del relieve con respecto a su cota media.

\subsubsection{Perfiles topográficos}

La variación latitudinal del grado de incisión se caracteriza mediante perfiles topográficos trazados con una orientación aproximadamente N-S en la Cordillera de la Costa. Se trazaron tres perfiles en los sectores occidental, central y oriental de la Cordillera de la Costa. Un cuarto perfil fue realizado en la Depresión Intermedia con el objetivo de establecer comparaciones con aquellos de la Cordillera de la Costa (Fig. 2).

Del análisis de estos perfiles, destaca como rasgo topográfico longitudinal de gran escala (mayor a $100 \mathrm{~km}$ ), que las cotas medias experimentan escalonamientos del orden de 200 a 1.000 m cada $\sim 250$ $\mathrm{km}$ de longitud. No se observa un cambio progresivo hacia una mayor o menor elevación en sentido N-S de las cotas medias; por el contrario, se alternan segmentos de mayor y menor cota media. Se pueden considerar tres segmentos longitudinales principales que son observables en los tres perfiles considerados para la Cordillera de la Costa, $\mathbf{S}_{1}: 18,5^{\circ}-21,3^{\circ} \mathrm{S} ; \mathbf{S}_{2}$ : $21,3^{\circ}-23,5^{\circ} \mathrm{S}$ y $\mathbf{S}_{3}: 24^{\circ}-27^{\circ} \mathrm{S}$ los cuales, en general, se puede considerar que presentan una morfología cóncava hacia abajo, existiendo subsegmentos que se indican con líneas segmentadas. El patrón de variación de las cotas en la Depresión Intermedia ilustrado en el Perfil 4 solo coincide con el de la Cordillera de la Costa entre los $18,5^{\circ}-19^{\circ} \mathrm{S}$ y entre los $23^{\circ}-27^{\circ} \mathrm{S}$; 
entre los $19^{\circ}-23^{\circ} \mathrm{S}$ existe una disminución de las cotas hacia la parte central de este segmento tanto desde el norte como desde el sur hasta los $21,3^{\circ} \mathrm{S}$ donde se localiza el valle del río Loa.

Las mayores cotas en el área de estudio se localizan $100 \mathrm{~km}$ al sur de Antofagasta $\left(24,5^{\circ} \mathrm{S}\right)$, donde la elevación de la Cordillera de la Costa alcanza una cota media de $2.000 \mathrm{~m}$ s.n.m. Esta alta elevación coincide también con una mayor altura de la Depresión Intermedia en el tramo considerado (Fig. 2, perfil 4). Un segundo máximo en la topografía ( $1.700 \mathrm{~m}$ s.n.m.) se observa entre los ríos Loa y Tocopilla $\left(21,7^{\circ}-22,5^{\circ} \mathrm{S}\right)$ donde además existe con un incremento paulatino de la elevación de la Depresión Intermedia hacia el sur (Perfil 4). Cotas máximas relativas pueden observarse también en el segmento de más al norte $\left(19^{\circ}-20^{\circ} \mathrm{S}\right)$ presentando mayores alturas la Cordillera de la Costa y un paulatino incremento de la elevación de la Depresión Intermedia, esta vez hacia el norte.
Los subsegmentos de menor cota media se localizan entre Iquique y las inmediaciones del Salar Grande $\left(20^{\circ}-21,7^{\circ} \mathrm{S}\right)$, y en la Cordillera de la Costa cerca de Antofagasta $\left(23,5^{\circ}-24^{\circ} \mathrm{S}\right)$. El primero de ellos (1.000 m s.n.m.) coincide con una disminución de la topografía de la Depresión Intermedia, y la presencia de los Salares de Llamara, Salar Grande y la cuenca del río Loa. El segundo de ellos afecta también a la Depresión Intermedia con cotas medias de $600 \mathrm{~m}$ s.n.m. y se corresponde con la depresión donde se desarrolla el Salar del Carmen inmediatamente al este de Antofagasta. Vistos en planta, estos mínimos de altura media en la Depresión Intermedia exponen una morfología de cuenca de drenaje, siendo los correspondientes mínimos de altitud media en la Cordillera de la Costa, sus correspondientes zonas de desagües hacia la costa. No obstante, las superficies del paisaje de estos desagües se encuentran colgadas en la parte alta del Acantilado Costero.
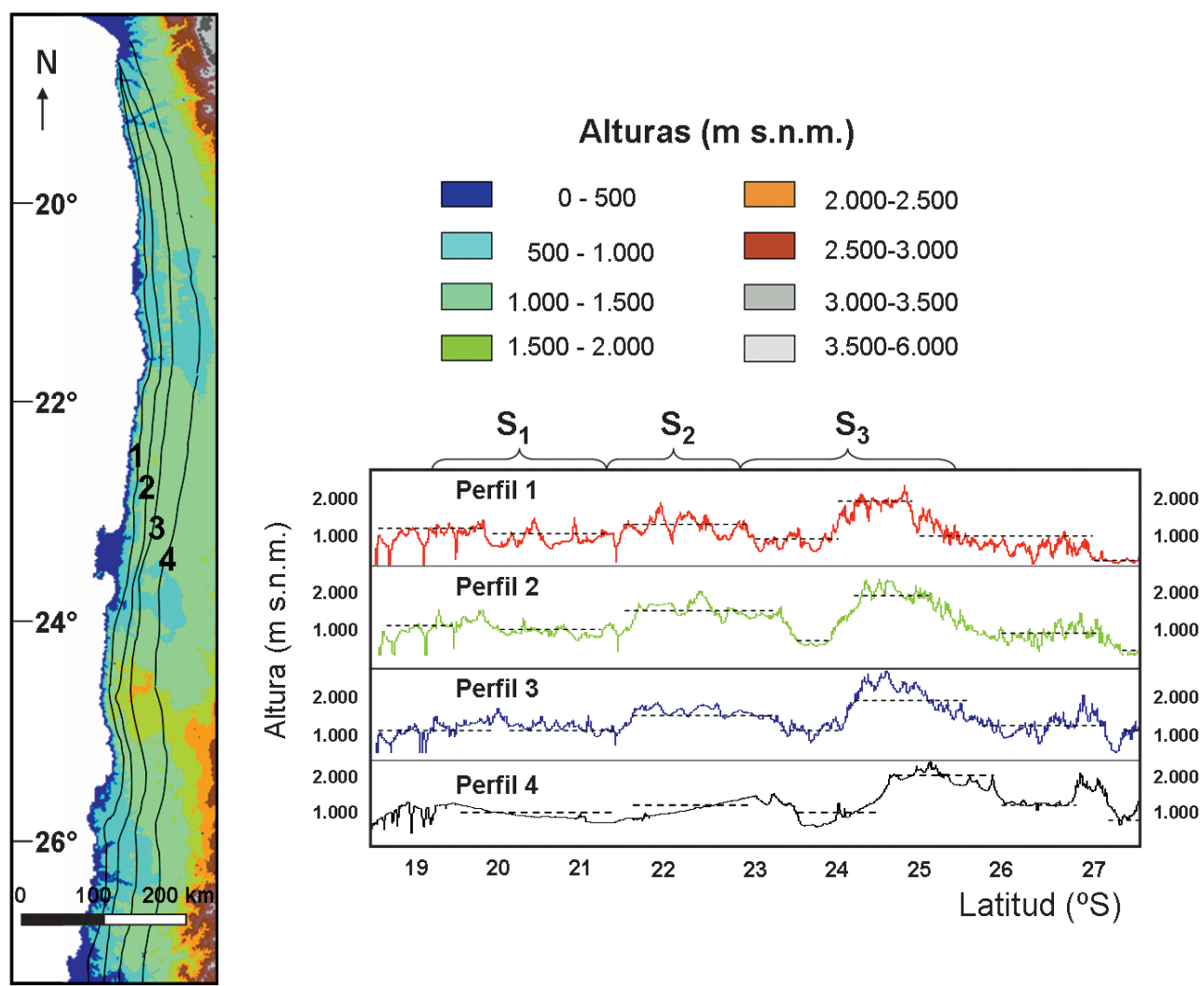

FIG. 2. Perfiles topográficos longitudinales en la Cordillera de la Costa y Depresión Intermedia. Se indican los tres segmentos longitudinales principales en la Cordillera de la Costa y las cotas medias de los subsegmentos en líneas discontinuas. 
Las cotas mínimas relativas que se presentan a los $23,5^{\circ} \mathrm{S}$ coinciden con un límite de los segmentos Salar del Carmen y Paposo del SFA, sin embargo, solo se observa una disminución gradual de las cotas hacia el sur entre los $25^{\circ}-25,5^{\circ} \mathrm{S}$, zona que separa los segmentos Paposo y Salado del SFA. No se puede considerar que las cotas más elevadas en la Cordillera de la Costa tengan alguna correspondencia o relación directa con los escarpes más altos del SFA, por cuanto en la zona comprendida entre los $21,5^{\circ}-23,5^{\circ} \mathrm{S}$, los escarpes más altos del Segmento Salar del Carmen del SFA se presentan entre los $22,5^{\circ}-23,5^{\circ} \mathrm{S}$ mientras que las cotas más elevadas de la Cordillera de la Costa se presentan entre los $21,5^{\circ}-22,5^{\circ} \mathrm{S}$. En la zona comprendida entre los $24^{\circ}-27^{\circ}$, se presentan los Segmentos Paposo y Salado del SFA y como se mencionó anteriormente, no se evidencia un cambio significativo en las cotas en el límite de ambos segmentos del SFA y al sur de $\operatorname{los} 26^{\circ} \mathrm{S}$, las cotas de la Cordillera de la Costa aumentan levemente en una zona de mayor desarrollo de escarpes del sistema Salado del SFA, los cuales se presentan muy erosionados. Las cotas más altas de la Cordillera de la Costa alrededor de los $24,5^{\circ} \mathrm{S}$ coinciden con la mayor altura de los escarpes de las fallas Paposo e Izcuña del segmento Paposo del SFA. No obstante lo anterior, estas cotas mayores de la Cordillera de la Costa que constituyen su máximo absoluto, también se presentan en el Perfil 4 al este de las trazas, es decir, las fallas del segmento Paposo del SFA afectaron una topografía alta de la Cordillera de la Costa que fue generada con anterioridad a la actividad de estas fallas. Se puede considerar que el SFA afectó una topografía de la Cordillera de la Costa que presentaba variaciones latitudinales de altura.

Lo anterior sugiere que la segmentación de gran escala que presenta la topografía longitudinal de la Cordillera de la Costa, es una herencia temprana en la configuración actual de paisaje. Esta herencia se asocia a factores que controlan la configuración morfológica de toda la región de antearco, y no solo de la Cordillera de la Costa.

Como rasgos de menor escala se tienen valles o quebradas de 50-300 $\mathrm{m}$ de ancho, y con diferencias de altitud (relieve local) de 100-500 m. En la parte norte de la Cordillera de la Costa, entre los $18,5^{\circ} \mathrm{y}$ $20^{\circ} \mathrm{S}$, estas incisiones son más profundas, del orden de $700 \mathrm{~m}$ en relieve local y espaciadas regularmente; corresponden a las grandes quebradas alimentadas por precipitaciones de la alta cordillera (Higuera, Vítor,
Camarones y Tiliviche) que inciden transversalmente todo el relieve de la región de antearco. Por lo tanto, ellas no son consecuencia de procesos erosivos ligados a precipitaciones en la Cordillera de la Costa. Más al sur, el río Loa $\left(21,3^{\circ} \mathrm{S}\right)$ también constituye una incisión de estas características (Fig. 1). A partir de los $23,7^{\circ} \mathrm{S}$, los rasgos de menor escala de la topografía de la Cordillera de la Costa muestran un paulatino incremento en la incisión del relieve con un progresivo mayor desarrollo de quebradas hacia el sur. Estas quebradas tienen un ancho de $\sim 100 \mathrm{~m}$ y la profundidad del valle es muy variable 20-200 m. Algunas superficies antiformes asociadas al sistema de fallas inversas de rumbo E-O pueden distinguirse a esta escala como elevaciones positivas sobre la cota media, destacando aquella a los $19,2^{\circ} \mathrm{S}$, asociada a la Falla Atajaña que se observa en los perfiles 1, 2 y 3, más nítidamente en el Perfil 2. Esta superficie antiforme así como el escarpe asociado a esta falla, son los que presentan mayores dimensiones de este sistema de fallas inversas E-O en la Cordillera de la Costa.

Análisis cuantitativos de estos cuatro perfiles topográficos fueron realizados por Seron et al. (2006) mediante la aplicación de ondeletas ('wavelets'), pudiendo correlacionarse mediante esta técnica los segmentos aquí presentados con las actuales variaciones latitudinales de la precipitación.

\subsubsection{Variaciones con respecto a la cota media}

El grado de incisión puede estimarse también como una variación del relieve con respecto a su cota media. La cota media corresponde a una superficie relativamente plana, formada por las alturas medias del relieve. Las cumbres importantes están por sobre esta cota media formando un relieve positivo, mientras que las depresiones constituidas por valles y quebradas forman un relieve negativo con respecto a la cota media (Fig. 3). El grado de incisión así definido corresponde a la diferencia entre la topografía del relieve y la cota media. Las incisiones propiamente tales forman las variaciones negativas. La incisión es mayor si existe una cota positiva muy elevada adyacente a una depresión importante. Para el cálculo del grado de incisión se consideró la topografía digital SRTM 90 (USGS) de la zona de antearco, comprendida entre $\operatorname{los} 18,5^{\circ}-27,5^{\circ} \mathrm{S}$, desde el litoral hasta el límite occidental de la Cordillera de los Andes. Para obtener la cota media del relieve, se realizó una convolución matricial utilizando una 
ventana deslizante de acuerdo al procedimiento utilizado por Bonnett (1996), con un tamaño de 61x61 pixeles que permite visualizar rasgos topográficos de mayor detalle. Posteriormente, se realizó la sustracción de la topografía del relieve y la topografía media obtenida mediante el procedimiento anterior, como se ilustra en la figura 3.

Para los fines de descripción, en este estudio las cotas positivas $>200 \mathrm{~m}$ se consideran como muy elevadas; cotas positivas de entre 0 y $200 \mathrm{~m}$ se denominan como cotas positivas moderadas. Equivalentemente, cuando la incisión varía entre 0 y -200 m se considera como incisión moderada. Por último, en el caso que la incisión supere $-200 \mathrm{~m}$ se designa como incisión fuerte (Fig. 3). En la figura 4 se ilustra la incisión del relieve en el área de estudio mediante el procedimiento indicado. La figura 5 representa ampliaciones de zonas específicas donde se puede visualizar mayor detalle. Se pueden distinguir tres tipos en los patrones de incisión. 1. El primer patrón corresponde al curso inferior de drenajes transversales que se extienden desde la Precordillera hasta el Océano Pacífico, constituyen las quebradas de Azapa, Higuera, Vítor, Camarones y Tiliviche, entre $18,5-20^{\circ} \mathrm{S}$ (Fig. 5a), y más al sur el río Loa y río Salado (Fig. 4). La incisión de estos drenajes en la Cordillera de la Costa es muy fuerte y, como se mencionó anteriormente, está controlada por las precipitaciones provenientes de la alta cordillera. 2. El segundo patrón lo definen incisiones que poseen un control por parte de las principales estructuras de la Cordillera de la Costa como el SFA, fallas inversas de orientación E-O y fallas de rumbo de orientación
NNO-SSE (Fig. 5). Estas incisiones coinciden con las trazas de estas fallas y se generan por las variaciones topográficas asociadas a los escarpes de falla y los bloques que ascienden y descienden. Por otro lado, en este patrón se incluyen también sistemas de drenaje que atraviesan la Cordillera de la Costa, en los cuales la incisión está controlada por ramas del SFA. Estos drenajes poseen un grado de incisión mayor al oeste que al este de estas fallas (Fig. $5 c)$. Este segundo patrón de incisiones claramente refleja un control estructural del SFA en el relieve de la Cordillera de la Costa. En particular, el control del grado de incisión para el segmento El Salado $\left(25,5^{\circ}-27^{\circ} \mathrm{S}\right)$ ha sido atribuido a la actividad Neógena del SFA, que alza en forma relativa el bloque occidental de la Cordillera de la Costa (Riquelme et al., 2003). Es a la escala reflejada por este tipo de incisiones, donde se puede determinar el efecto de la herencia geomorfológica, que pueda deberse a la actividad tectónica antigua o al control litológico de la geomorfología.

El tercer patrón corresponde a las redes de drenaje que se desarrollan en la vertiente occidental de la Cordillera de la Costa. Se observan claramente como rasgo de menor escala asociado a incisiones moderadas entre $18,5^{\circ} \mathrm{S}$ y $22^{\circ} \mathrm{S}$ (Figs. 4,5 a y 5 b); y fuertes para el tramo entre los $22^{\circ}$ y $27^{\circ} \mathrm{S}$. Estas últimas destacan en la figura $5 \mathrm{c}$ al sur de Paposo. El crecimiento de las redes de drenaje que dan origen a este tipo de incisiones no está afectado por la actividad local del SFA. Al sur de los $25,5^{\circ} \mathrm{S}$, estos drenajes cortan las trazas del SFA (Fig. 4). La propagación de la incisión al interior de estos sistemas de drenaje

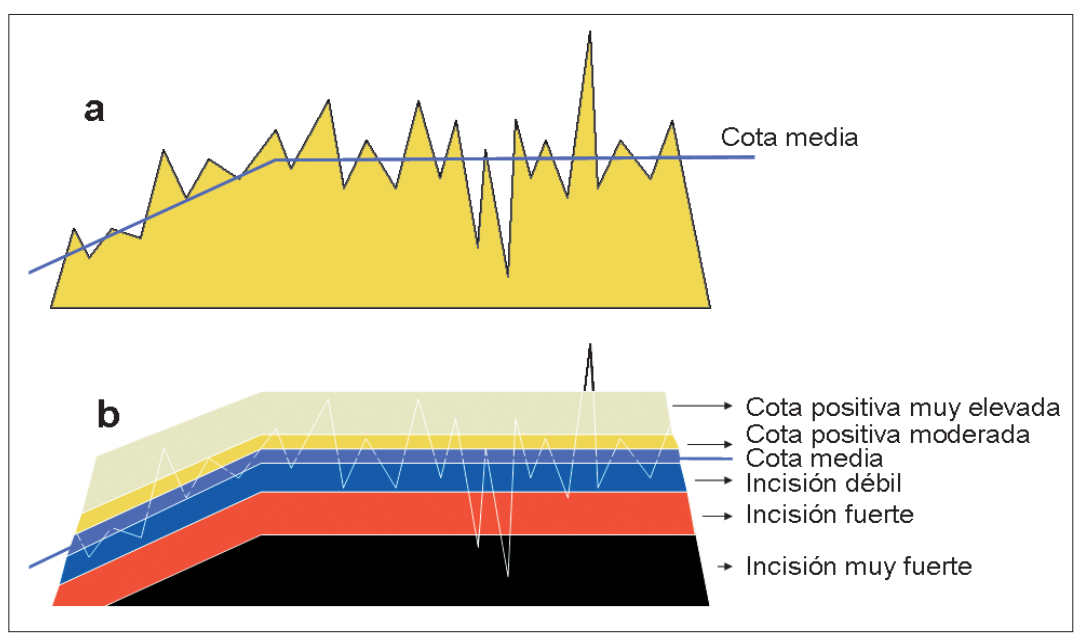

FIG. 3. Procedimiento para el cálculo de la incisión del relieve. En a. se ilustra la topografía y en b. la categorización de la incisión en la topografía: Incisión=Topografía-Cota media. 


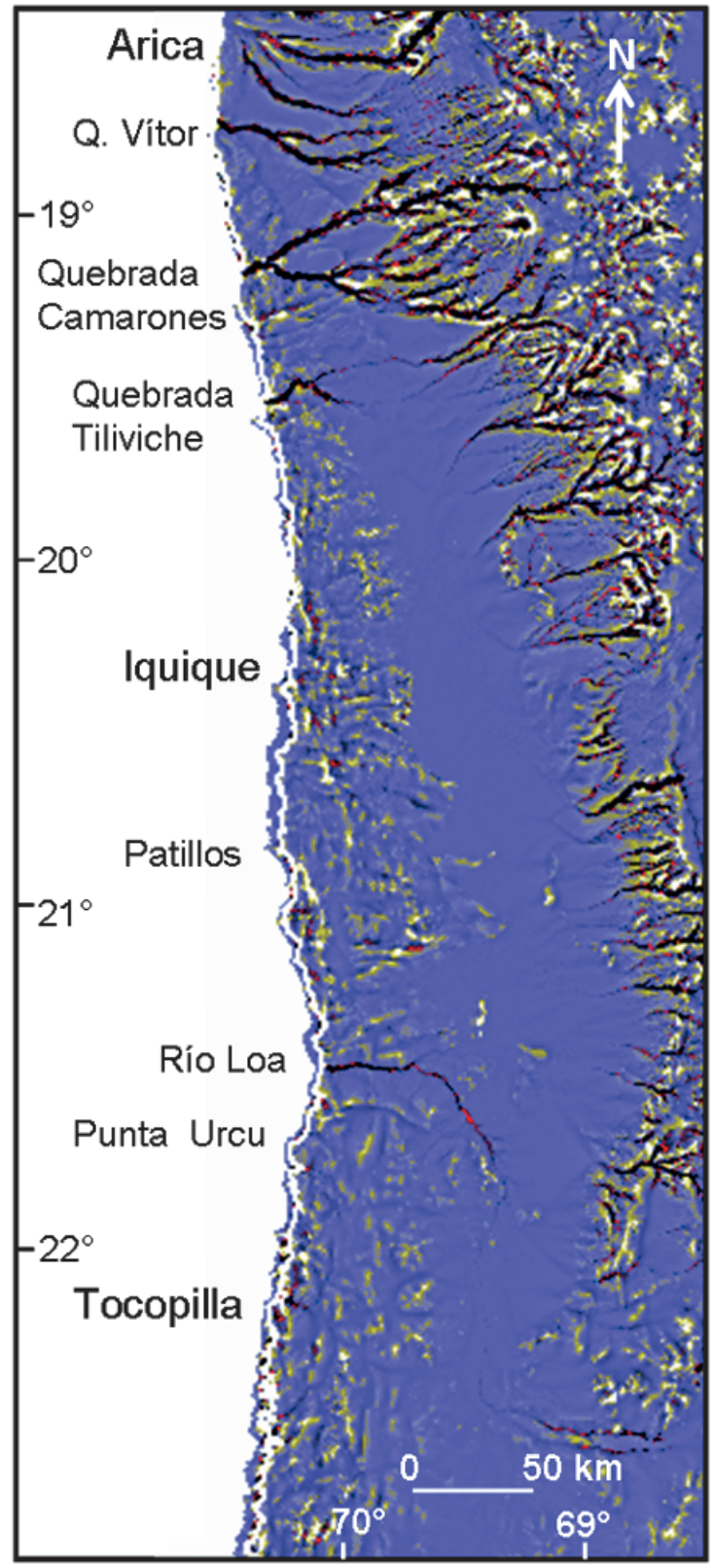

Cota positiva muy elevada

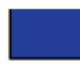

Incisión débil

Cota positiva

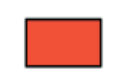

Incisión

fuerte

Cota media

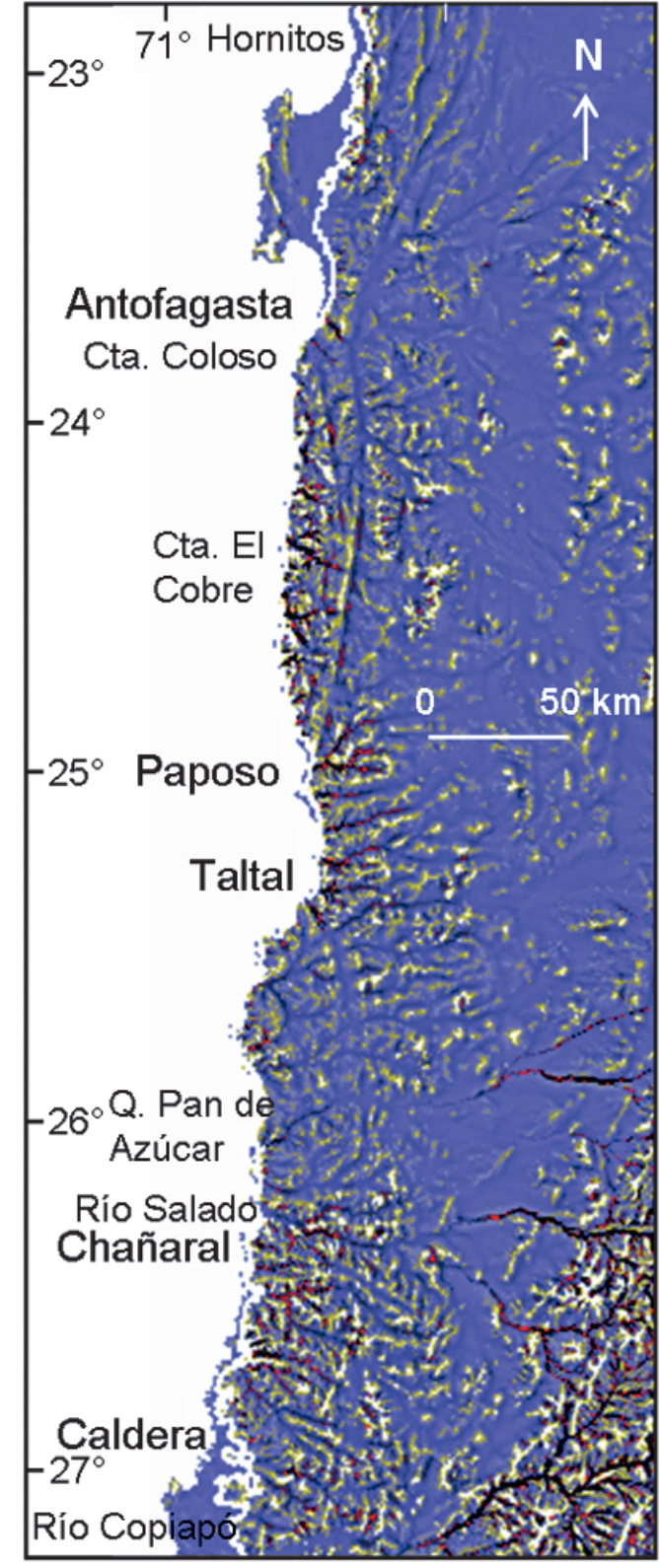

FIG. 4. Mapa de incisiones del área de estudio realizadas mediante convolución matricial. Destacan en el extremo norte incisiones en dirección E-O correspondientes a las quebradas que se presentan entre Arica e Iquique, más al sur destacan también los ríos Loa y Salado y la quebrada Pan de Azúcar. Se distinguen las incisiones generadas por los sistemas estructurales en la Cordillera de la Costa, especialmente el SFA. Al sur de los $26^{\circ} \mathrm{S}$, no se distinguen los rasgos originales del relieve ni tampoco las trazas del SFA y los drenajes presentan un gran desarrollo y jerarquía. Línea blanca señala la base del Acantilado Costero. 

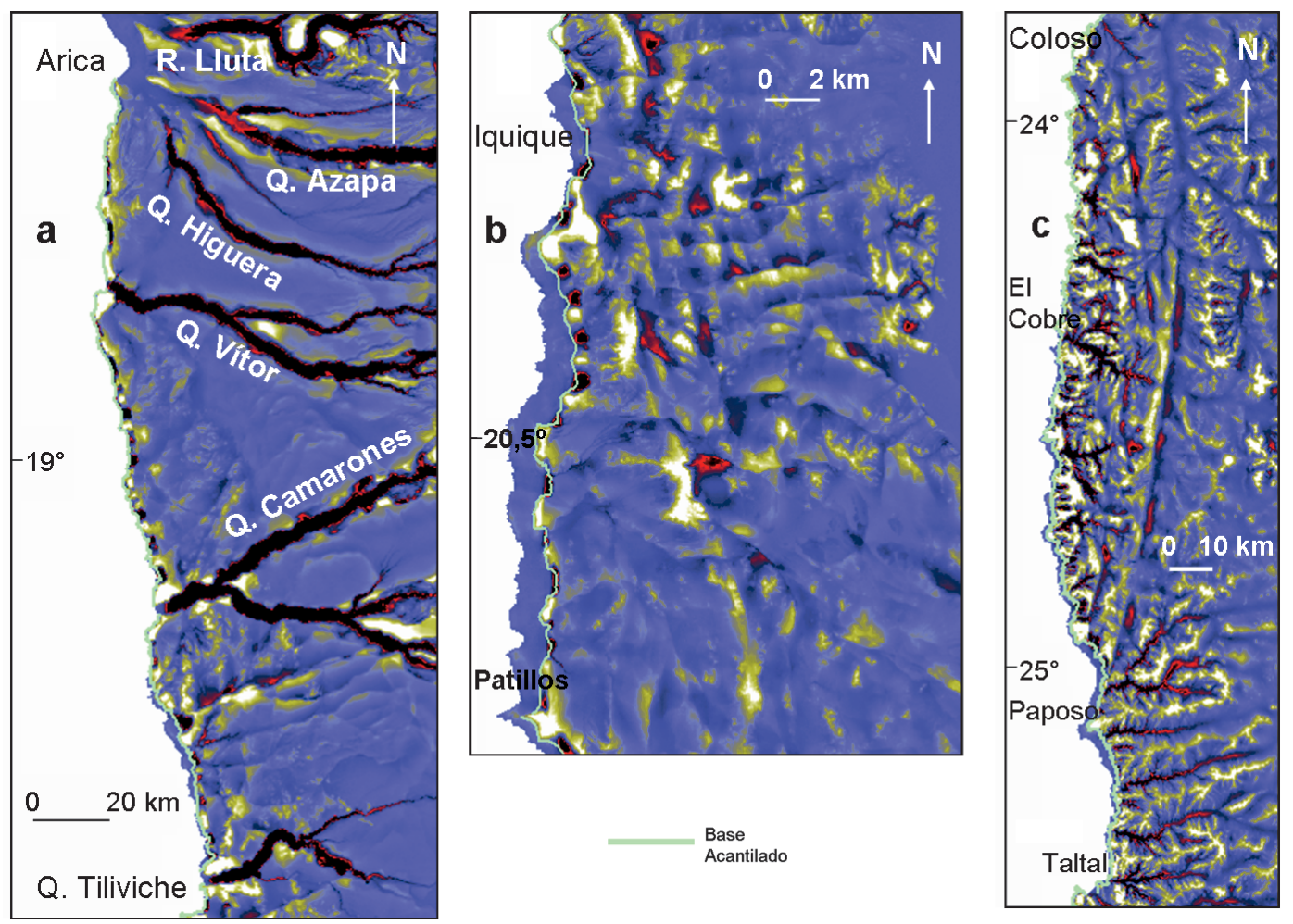

FIG. 5. Zonas de detalle. a. Extremo norte del área de estudio. Destacan las incisiones muy fuertes de las grandes quebradas que se extienden desde fuera del ámbito de la Cordillera de la Costa; entre las quebradas Camarones y Tiliviche destacan las incisiones en la Cordillera de la Costa correspondientes a fallas inversas de orientación aproximada E-O; b. Sur de Iquique. Destaca la casi ausencia de quebradas que descienden por el Acantilado Costero y las incisiones asociadas a los diferentes sistemas de fallas presentes en la Cordillera de la Costa resaltando los de orientación NNO-SSE, los de orientación E-O que corresponden a fallas inversas y en la zona más oriental y en la zona sur, incisiones de orientación N-S que pueden asociarse al SFA; c. Sur de Antofagasta. Destacan las incisiones de orientación meridiana entre Coloso y Paposo asociadas al SFA, la más oriental corresponde a la Falla Paposo. Las incisiones son mayores al oeste de las trazas. Entre Paposo y Taltal destacan incisiones fuertes a muy fuertes de orientación E-O que se propagan al E.

puede estar controlada por cambios en el nivel de base en el Acantilado Costero -de origen tectónico o eustático- o por variaciones climáticas durante su evolución. Son las cuencas de drenaje que contienen estas incisiones las que deben registrar los efectos del alzamiento o las variaciones climáticas latitudinales.

\subsection{Curva e integral hipsométrica}

La curva hipsométrica describe la distribución de elevaciones en una cuenca de drenaje (Strahler, 1952; Keller y Pinter, 1996). Se construye graficando las alturas relativas y áreas relativas. Para una cota determinada (h), el área relativa es la fracción del área (a) sobre esa cota (h) respecto al área total (A) de la cuenca. La altura relativa es la correspon- diente a la cota $(\mathrm{h})$, dividida por la altura total $(\mathrm{H})$ de la cuenca (Fig. 6a). Esta curva representa, para altitudes decrecientes, la porción de la superficie de la cuenca para la cual las altitudes son mayores que una altitud determinada (Figs. 6b y 6c). Para efectos de comparación entre distintas cuencas, la curva hipsométrica se presenta normalizada en relación tanto al área como a la altitud máxima de la cuenca. Considerando un análisis de cuencas de drenaje del orden de las decenas de kilómetros cuadrados, Strahler (1952) demostró que las curvas hipsométricas pueden usarse para deducir las etapas de evolución geomorfológica de las cuencas de drenaje. Una curva hipsométrica convexa representa una cuenca que tiene una gran proporción de su superficie situada a altitudes elevadas. Se trata 
de una curva correspondiente a un paisaje juvenil ('youthful stage', curva 1, Fig. 6b), por ejemplo, una cuenca incidida formada por una superficie de erosión alzada y luego disectada. Por el contrario, una curva hipsométrica cóncava representa una cuenca que tiene un relieve de baja amplitud en su elevación y posee más bien bajas altitudes; corresponde a un relieve senil en la etapa de formación de peniplanicies ('peneplain stage'; curva 3, Fig. 6b). Los casos intermedios, caracterizados por curvas sinusoidales cóncavo-convexo representan estados transitorios en la evolución del relieve, desde la madurez a un estado de paisaje antiguo ('mature and old stages'; curva 2, Fig. 6b). Mientras la inflexión en la curva, de cóncava a convexa se presente a alturas relativas mayores, menor será el grado de evolución del relieve y mayor el porcentaje del paisaje preservado original. La curva hipsométrica da cuenta de la influencia de los factores tectónicos, climáticos y el control de la litología sobre la evolución de las cuencas de drenaje. Sin embargo, existen discrepancias sobre la importancia relativa de cada uno de estos factores que son más bien ligadas a la talla de las cuencas de drenaje consideradas (e.g., Strahler, 1952; Ohomori, 1993; Willgoose, 1994; Keller y Pinter, 1996). La integral hipsométrica es una medida cuantitativa de la curva hipsométrica y corresponde al área bajo la curva hipsométrica (Fig. 6c). Integrales mayores a 0,5 se asocian a curvas convexas que indican estadios juveniles con predominio del proceso de alzamiento de la superficie o de las rocas sobre los procesos de erosión. Integrales menores a 0,5 se asocian a una curva con morfología cóncava e indican predominio de procesos erosivos sobre los tectónicos. Mientras que curvas con integrales cercanas a 0,5 , se asocian a curvas de morfología sinusoidal cóncavo-convexas e indican que los procesos tectónicos y erosivos están balanceados (Keller y Pinter, 1996).

Debido a que la curva e integral hipsométrica constituyen indicadores del predominio de la componente tectónica y climática de los relieves, se consideró aplicarlos a la vertiente occidental de la Cordillera de la Costa, es decir, a drenajes que descienden por el Acantilado Costero. Con el objetivo de determinar las variaciones latitudinales de la integral hipsométrica y asociar estas mismas a variaciones latitudinales de la componente tectónica, climática y el control litológico actuando sobre la evolución del paisaje, se escogieron 86 cuencas de la vertiente occidental de la Cordillera de la Costa (Tabla 2). En estas cuencas se determinó la integral hipsométrica utilizando cotas (h) cada $100 \mathrm{~m}$ sobre el nivel de base de la cuenca, i.e., el nivel del océano. Se pueden distinguir dos categorías de cuencas hidrográficas: 1. aquellas que tienen una superficie mayor a 100 $\mathrm{km}^{2}$ y que se extienden varios kilómetros al este del talud del Acantilado Costero (Fig. 7). Como fue expresado anteriormente, estas cuencas abarcan una topografía antigua de la Cordillera de la Costa. Lo anterior queda claramente en evidencia en algunas cuencas, donde los drenajes que escurrieron hacia el este están truncados por el retroceso hacia el este del talud del Acantilado Costero (Fig. 8a); y 2. aquellas que tienen una superficie inferior a $100 \mathrm{~km}^{2}$, que se restringen a las vecindades del talud del Acantilado Costero y que son las que potencialmente entregan información sobre las variaciones latitudinales climáticas y del alzamiento costero (Figs. 7 y 8b). a

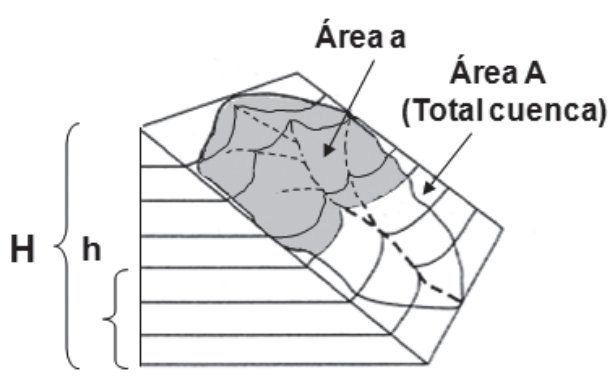

b

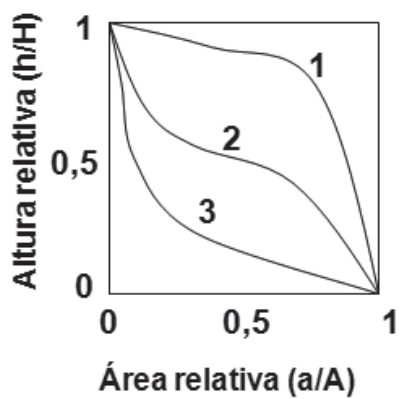

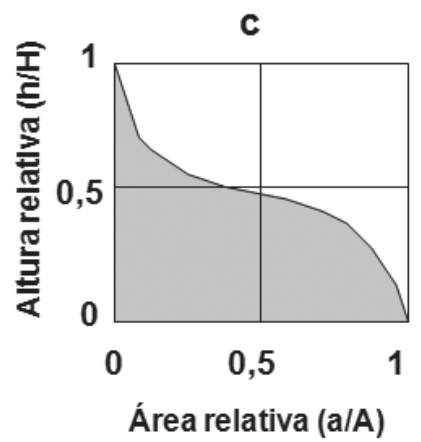

FIG. 6. Procedimiento para la determinación de la curva e integral hipsométrica. a. Ilustración del área a (sombreado) de una cuenca hidrográfica que se encuentra por sobre una cota h; b. Tipos de curvas hisométricas: 1 curva convexa, 2 curva sinusoidal, 3 curva cóncava; c. Integral hipsométrica: área bajo la curva hipsométrica (Modificado de Keller y Pinter, 1996). 
TABLA 2. INTEGRALES HIPSOMÉTRICAS PARA DRENAJES SELECCIONADOS QUE DESCIENDEN POR EL TALUD DEL ACANTILADO.*

\begin{tabular}{|c|c|c|c|c|c|c|c|c|c|}
\hline Cuenca & $\begin{array}{c}\text { Latitud } \\
\left({ }^{\circ} S\right)\end{array}$ & $\begin{array}{c}\text { Área A } \\
\left(\mathbf{k m}^{2}\right)\end{array}$ & $\begin{array}{c}\text { Altura H } \\
(\mathbf{k m})\end{array}$ & Integral & Cuenca & $\begin{array}{c}\text { Latitud } \\
\left({ }^{\circ} \mathbf{S}\right)\end{array}$ & $\begin{array}{c}\text { Área, A } \\
\left(\mathbf{k m}^{2}\right)\end{array}$ & $\begin{array}{c}\text { Altura } H \\
(\mathbf{k m})\end{array}$ & Integral \\
\hline $1 \mathrm{~B}$ & 19,2 & 27 & 1.400 & 0,57 & $7 \mathrm{G}$ & 23,4 & 293,9 & 1.400 & 0,42 \\
\hline $1 \mathrm{C}$ & 19,3 & 75,8 & 1.600 & 0,53 & $7 \mathrm{I}$ & 23,5 & 62,9 & 900 & 0,52 \\
\hline $1 \mathrm{E}$ & 19,4 & 138,7 & 1.500 & 0,55 & $7 \mathrm{~K}$ & 23,6 & 41,2 & 900 & 0,52 \\
\hline $1 \mathrm{G}$ & 19,5 & 52,9 & 1.300 & 0,55 & $7 \mathrm{M}$ & 23,7 & 51,1 & 1.000 & 0,43 \\
\hline $1 \mathrm{H}$ & 19,6 & 12,6 & 1.200 & 0,47 & $7 \mathrm{~N}$ & 23,7 & 28 & 800 & 0,44 \\
\hline $2 \mathrm{~A}$ & 19,7 & 52,3 & 1.400 & 0,47 & $7 \mathrm{P}$ & 23,7 & 83,3 & 1.000 & 0,4 \\
\hline $2 \mathrm{C}^{*}$ & 19,7 & 178 & 1.600 & 0,56 & $7 \mathrm{Q}$ & 23,8 & 238,8 & 1.200 & 0,41 \\
\hline $2 \mathrm{E}$ & 19,9 & 59,3 & 1.500 & 0,52 & $7 \mathrm{R}$ & 23,8 & 44,1 & 1.000 & 0,4 \\
\hline $2 \mathrm{H}$ & 20,2 & 18,9 & 1.100 & 0,51 & $8 \mathrm{~B}$ & 24 & 7,2 & 700 & 0,45 \\
\hline $2 \mathrm{I}$ & 20,2 & 16,6 & 1.100 & 0,49 & $8 \mathrm{C}^{*}$ & 24 & 139,7 & 1.600 & 0,45 \\
\hline $2 \mathrm{~J}$ & 20,2 & 52,4 & 1.200 & 0,51 & $8 \mathrm{D}^{*}$ & 24,1 & 25,5 & 1.400 & 0,46 \\
\hline $3 \mathrm{D}$ & 20,4 & 25,5 & 1.300 & 0,48 & $8 \mathrm{~F}$ & 24,2 & 1,8 & 1.100 & 0,44 \\
\hline $3 \mathrm{~F}$ & 20,4 & 38,9 & 1.100 & 0,48 & $8 \mathrm{H}$ & 24,2 & 13,4 & 2.100 & 0,45 \\
\hline $3 \mathrm{~J}$ & 20,6 & 70,6 & 1.300 & 0,46 & $8 \mathrm{I}$ & 24,3 & 3,5 & 1.600 & 0,44 \\
\hline $3 \mathrm{~K}$ & 20,6 & 70,1 & 1.200 & 0,46 & $8 \mathrm{~K}^{*}$ & 24,4 & 540,7 & 2.700 & 0,5 \\
\hline $3 \mathrm{~N}$ & 20,8 & 44,8 & 700 & 0,57 & $8 \mathrm{~L}$ & 24,4 & 21,8 & 1.600 & 0,41 \\
\hline $3 R^{*}$ & 20,8 & 113,7 & 1.000 & 0,51 & $8 \mathrm{M}$ & 24,5 & 59,9 & 1.900 & 0,42 \\
\hline $4 \mathrm{~A}$ & 20,9 & 43,6 & 1.500 & 0,44 & $8 \mathrm{~N}^{*}$ & 24,6 & 146,7 & 2.100 & 0,5 \\
\hline $4 B^{*}$ & 21 & 149,5 & 1.600 & 0,38 & $8 \mathrm{O}^{*}$ & 24,6 & 440,3 & 2.600 & 0,54 \\
\hline $4 D^{*}$ & 21,2 & 44,6 & 1.300 & 0,45 & $8 \mathrm{P}$ & 24,7 & 26,42 & 2.000 & 0,32 \\
\hline $4 \mathrm{H}$ & 21,4 & 14,8 & 900 & 0,49 & $8 \mathrm{R}^{*}$ & 24,8 & 274,6 & 2.400 & 0,56 \\
\hline $4 \mathrm{I}$ & 21,4 & 27,1 & 1.000 & 0,51 & $8 \mathrm{~S}$ & 24,8 & 44,1 & 2.100 & 0,47 \\
\hline $5 C^{*}$ & 21,5 & 65,5 & 1.400 & 0,55 & $9 \mathrm{~A}$ & 25,1 & 25,5 & 1.500 & 0,42 \\
\hline $5 \mathrm{D}$ & 21,6 & 13,7 & 1.300 & 0,44 & $9 \mathrm{~B}$ & 25,1 & 419,2 & 2.500 & 0,52 \\
\hline $5 \mathrm{~F}$ & 21,6 & 15,2 & 1.500 & 0,35 & $9 \mathrm{C}$ & 25,2 & 38,3 & 1.500 & 0,46 \\
\hline $5 \mathrm{G}$ & 21,6 & 19,4 & 1.400 & 0,43 & 9D & 25,2 & 1332,9 & 2.700 & 0,58 \\
\hline $5 \mathrm{~J}$ & 21,7 & 694,6 & 2.000 & 0,57 & $9 \mathrm{G}^{*}$ & 25,3 & 1723,5 & 2.700 & 0,59 \\
\hline $5 \mathrm{~K}$ & 21,8 & 15,8 & 1.000 & 0,49 & $9 \mathrm{H}^{*}$ & 25,4 & 415,4 & 2.000 & 0,48 \\
\hline $5 \mathrm{P}^{*}$ & 22,1 & 938,2 & 2.300 & 0,51 & $9 \mathrm{~N}$ & 25,7 & 1325,5 & 2.000 & 0,41 \\
\hline $5 Q^{*}$ & 22,1 & 90,9 & 1.600 & 0,45 & $9 \mathrm{P}^{*}$ & 25,8 & 29,4 & 700 & 0,47 \\
\hline $5 \mathrm{R}$ & 22,2 & 94,8 & 1.600 & 0,55 & $9 \mathrm{~T}$ & 25,9 & 164,7 & 1.100 & 0,51 \\
\hline $6 \mathrm{~A}$ & 22,3 & 22,7 & 1.500 & 0,48 & $9 \mathrm{~V}^{*}$ & 26 & 2565,9 & 2.700 & 0,45 \\
\hline $6 \mathrm{D}$ & 22,4 & 35,6 & 1.300 & 0,52 & $10 \mathrm{~A}$ & 26,2 & 22 & 600 & 0,49 \\
\hline $6 \mathrm{~F}^{*}$ & 22,5 & 147 & 1.800 & 0,5 & $10 \mathrm{~B}$ & 26,2 & 101,5 & 900 & 0,5 \\
\hline $6 \mathrm{G}$ & 22,6 & 24,3 & 1.500 & 0,44 & $10 \mathrm{C}$ & 26,3 & 714,5 & 1.500 & 0,47 \\
\hline $6 \mathrm{~L}$ & 22,8 & 19,7 & 900 & 0,53 & $10 \mathrm{~F}$ & 26,5 & 13,73 & 800 & 0,35 \\
\hline $6 \mathrm{O}$ & 22,8 & 26,8 & 1.200 & 0,47 & $10 \mathrm{G}^{*}$ & 26,5 & 88,6 & 900 & 0,44 \\
\hline $6 Q^{*}$ & 22,9 & 24,8 & 1.200 & 0,45 & $10 \mathrm{~J}$ & 26,5 & 184,3 & 1.400 & 0,37 \\
\hline $6 \mathrm{~V}$ & 22,9 & 8,9 & 1.200 & 0,4 & $10 \mathrm{M}^{*}$ & 26,6 & 74,2 & 1.000 & 0,41 \\
\hline $7 B^{*}$ & 23,2 & 1.413 & 1.900 & 0,46 & $10 \mathrm{~N}$ & 26,7 & 33,5 & 1.000 & 0,48 \\
\hline $7 \mathrm{C}$ & 23,3 & 100,9 & 1.400 & 0,39 & $10 \mathrm{O}$ & 26,8 & 48,7 & 1.000 & 0,44 \\
\hline $7 \mathrm{D}$ & 23,2 & 14,4 & 900 & 0,37 & $10 \mathrm{Q}$ & 26,8 & 1293,1 & 1.900 & 0,42 \\
\hline $7 \mathrm{E}$ & 23,3 & 61,9 & 1.200 & 0,31 & $10 \mathrm{R}$ & 26,9 & 13,8 & 600 & 0,5 \\
\hline
\end{tabular}

* Los drenajes marcados indican cuencas que abarcan drenajes antiguos que son truncados por el acantilado costero. 


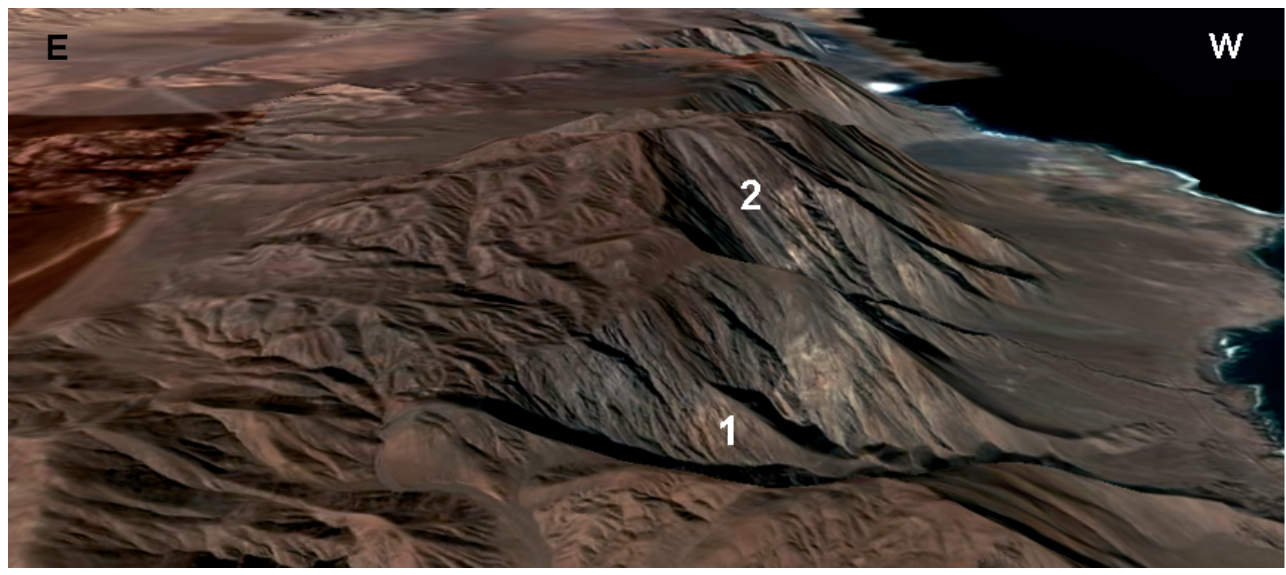

FIG. 7. Imagen $3 \mathrm{D}$ (NASA, Google Earth), vista hacia el sur del Acantilado Costero a los $22,5^{\circ} \mathrm{S}$. Destacan dos drenajes que descienden por el talud del Acantilado Costero, ambos con perfil de thalweg cóncavo hacia arriba. El drenaje 1 (más próximo) tiene una cuenca hidrográfica de mayor superficie que abarca una topografía antigua de la Cordillera de la Costa truncada por el talud del Acantilado Costero. El drenaje evidencia un rejuvenecimiento del paisaje en el talud. El drenaje 2 (más lejano) tiene una cuenca hidrográfica de menor superficie que se restringe solo al talud del Acantilado Costero y forma un abanico aluvial que cubre la plataforma de abrasión emergida en la base del Acantilado Costero. Este abanico fue truncado por el mar y presenta una incisión, visible en la imagen, que se extiende desde la base del Acantilado Costero hasta el litoral.
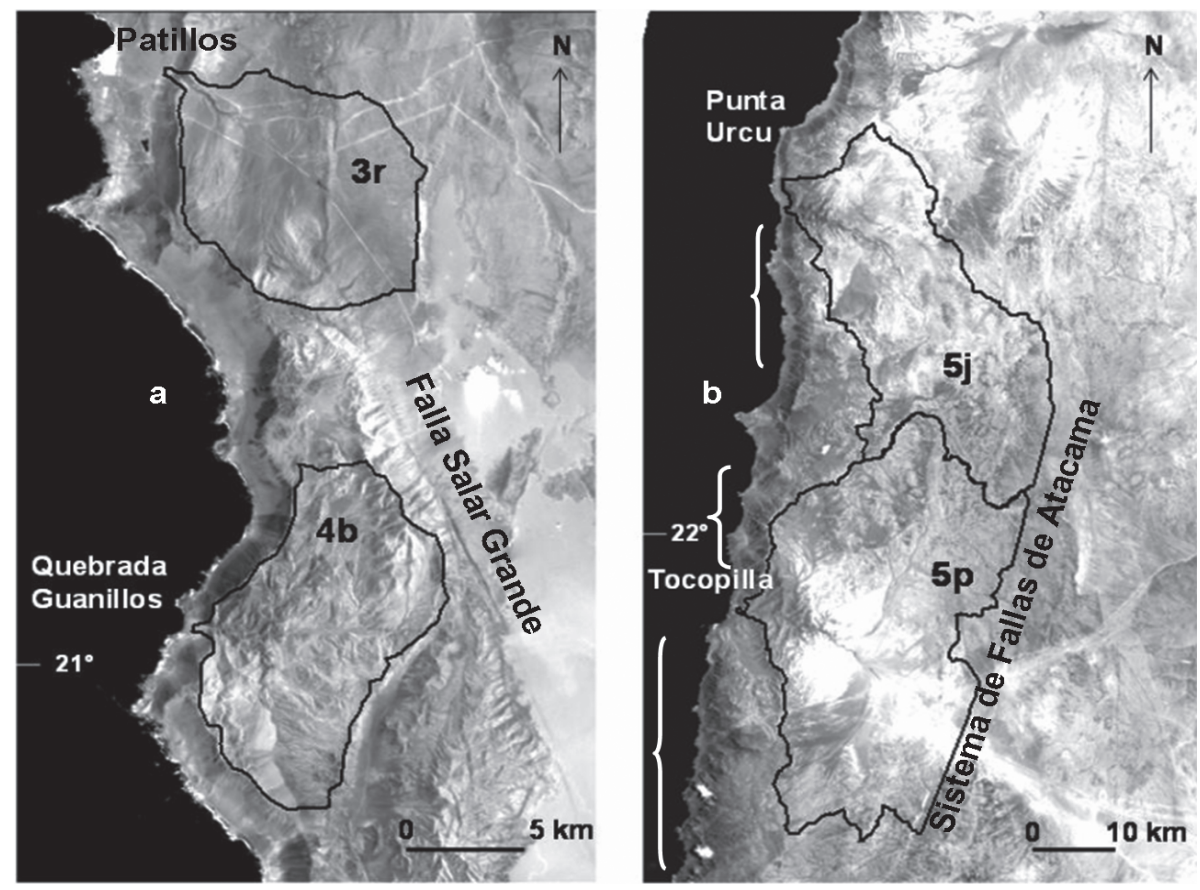

FIG. 8. Área de las cuencas hidrográficas de algunos drenajes considerados en el análisis hipsométrico. a. Drenajes que descienden por el talud del Acantilado Costero con cuencas hidrográficas delimitadas al oeste por el talud del Acantilado Costero. Algunos drenajes que escurren al este son truncados por el talud del Acantilado Costero evidenciando una topografía ya erosionada que se ubicaba al oeste del talud actual. La cuenca $4 \mathrm{~b}$ es delimitada al este por serranías controladas por la Falla Salar Grande; $\mathbf{b}$. Incisiones de las quebradas $5 \mathrm{j}$ y $5 \mathrm{p}$ que avanzan hacia el este producto del descenso del nivel de base. Las cuencas hidrográficas tienen una gran superficie que se extiende hacia el este. Este límite rectilíneo está controlado por el SFA. Las áreas grandes de las cuencas hidrográficas ilustradas limitan el área de las cuencas vecinas, de modo que la mayoría de los drenajes que descienden por el Acantilado Costero (señalados por paréntesis de llaves), tienen cuencas hidrográficas con áreas menores a $100 \mathrm{~km}^{2}$. 
La figura 9 ilustra el área de las cuencas hidrográficas consideradas versus la latitud. Se puede distinguir que las cuencas hidrográficas de áreas menores a $100 \mathrm{~km}^{2}$ se encuentran presentes en toda el área de estudio, mientras que las cuencas que presentan una superficie mayor tienen una distribución más localizada. Estas cuencas mayores, entre $\operatorname{los} 22^{\circ}$ y $25^{\circ} \mathrm{S}$, están limitadas principalmente por altos topográficos controlados por estructuras como el SFA, que impiden su extensión hacia el este (Figs. 5c y 8b). Entre los $25^{\circ}$ y $27^{\circ} \mathrm{S}$, ellas atraviesan completamente la Cordillera de la Costa, extendiéndose hacia el este de las trazas del SFA(Fig. 5). En general, se observa que la ocurrencia de cuencas con superficies mayores limita el área de captura de las cuencas que descienden por el talud del Acantilado Costero (Figs. 7, 8b).

La figura 10 muestra el valor de la integral hipsométrica en función de la latitud, para las cuencas de drenaje mayores a $100 \mathrm{~km}^{2}$. En ella se observa que al norte de los $23^{\circ} \mathrm{S}$ el valor de la integral hipsométrica fluctúa entre 0,5 y 0,6 . En cambio, al sur de $\operatorname{los} 23^{\circ} \mathrm{S}$ el valor de la integral hipsométrica presenta una variación entre 0,35 y 0,6. La figura 11 ilustra cinco curvas hipsométricas representativas de las cuencas ubicadas al norte y sur de los $23^{\circ} \mathrm{S}$. Las cuencas situadas al norte (Fig. 11a) exponen una geometría sigmoidea cóncavo-convexa, con puntos de inflexión ubicados para alturas relativas $(0,4)$ más bien bajas. Por otra parte, el tramo cóncavo de estas curvas es relativamente plano. Las curvas situadas al sur de los $23^{\circ} \mathrm{S}$ (Fig. 11b) son aproximadamente cóncavas, o bien sigmoideas cóncavo-convexas, pero esta vez con la inflexión a alturas relativas mayores que aquellas de las cuencas del norte.

El tramo cóncavo de las curvas ubicadas al norte de los $23^{\circ} \mathrm{S}$ refleja un relieve maduro que posee variaciones de altitud bajas. La observación de la geomorfología a gran escala de la región correspondiente, indica que este relieve maduro corresponde al pediplano de Tarapacá, señalado por Mortimer et al. (1974). Este paisaje maduro tiene un rejuvenecimiento asociado a los sistemas que drenan hacia el océano (drenaje 1, Fig. 7), que presentan básicamente incisión vertical con poco desarrollo en área en el talud del Acantilado Costero, lo que se traduce en una inflexión de la curva hipsométrica para alturas relativas más bien bajas. Se trata entonces de un paisaje peniplanizado, que se encuentra colgado y afectado prácticamente solo por incisión vertical. Para este tramo, una excepción corresponde a una

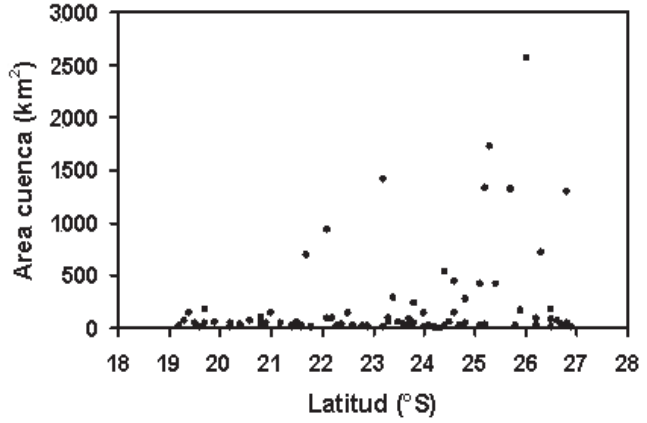

FIG. 9. Distribución de las áreas de las cuencas hidrográficas de los drenajes que descienden por el Acantilado Costero versus latitud. Las cuencas de gran superficie se presentan entre $\operatorname{los} 21,5^{\circ}-27^{\circ} \mathrm{S}$, en cambio las cuencas de menor superficie están presentes en toda el área de estudio y en mayor cantidad.

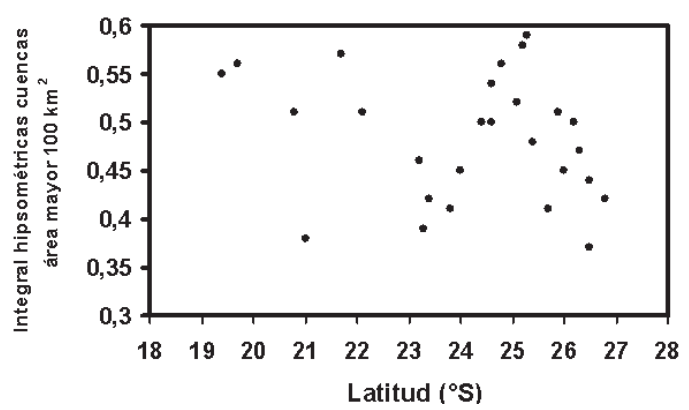

FIG. 10. Distribución de las integrales hipsométricas de área mayor a $100 \mathrm{~km}^{2}$ de las cuencas versus latitud. Al norte del área de estudio predominan las integrales con valores altos y más al sur existen valores altos y más bajos.

cuenca compuesta solo por paisaje maduro colgado sin desarrollo de incisión vertical, lo que se refleja en un bajo valor de integral -0,38- (cuenca 4b, Fig. $8 \mathrm{a}$ ). Al sur de los $23^{\circ} \mathrm{S}$, los valores de las integrales son primero crecientes y luego decrecientes con la latitud, siguiendo la tendencia de las alturas medias (Figs. 2 y 10). Aquellas cuencas con mayores valores de la integral hipsométrica se localizan en el segmento que expone una mayor altura. Las curvas hipsométricas asociadas a estas curvas poseen geometrías sigmoideas (Fig. 11a), pero con un punto de inflexión localizado a alturas relativas altas, reflejando el tramo cóncavo pequeños remanentes de un paisaje peniplanizado (Fig. 7). Las cuencas ubicadas más al sur poseen curvas hipsométricas más cóncavas (Fig. 11b), reflejando un mayor grado de evolución de los sistemas de drenaje, los que han erosionado casi completamente los relictos de un paisaje original. 

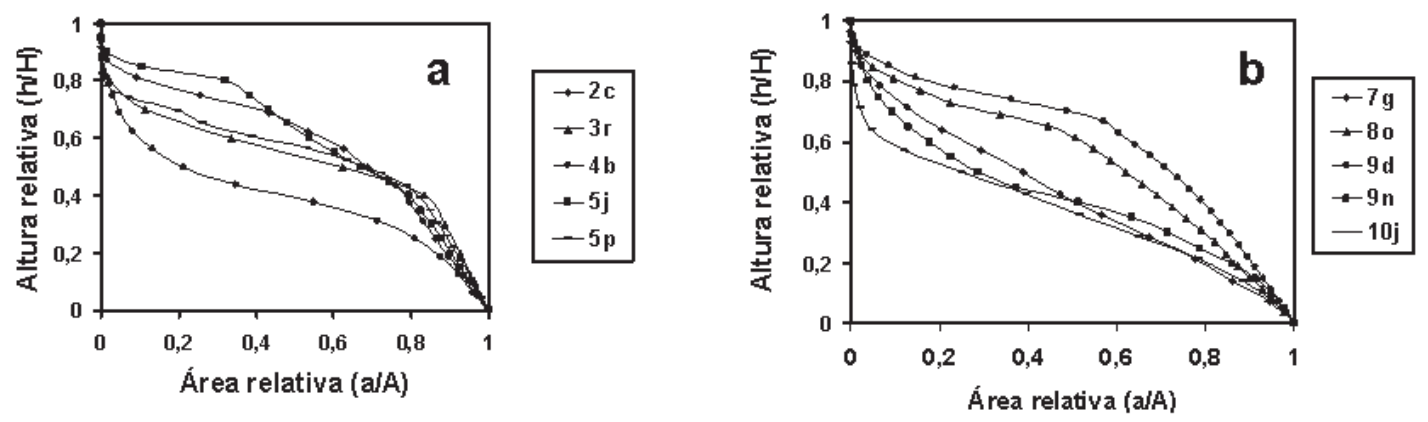

FIG. 11. Curvas hipsométricas de drenajes con cuencas hidrográficas de superficie mayor a $100 \mathrm{~km}^{2}$. a. $\mathrm{Al}$ norte de los $23^{\circ} \mathrm{S}$ destaca el cambio de pendiente de las curvas a una cota relativa 0,4 y la concavidad a cotas relativas altas; $\mathbf{b}$. Al sur de los $23^{\circ} \mathrm{S}$ destacan las curvas convexas asociadas a los drenajes 80 y $9 \mathrm{~d}$ mientras que las demás son más cóncavas.

La figura 12 muestra el valor de la integral hipsométrica en función de la latitud para las cuencas de drenaje menores a $100 \mathrm{~km}^{2}$. En ellas se observa que la magnitud de las integrales que predominan en toda el área de estudio es de 0,4-0,5 que es un valor intermedio. Sin embargo, al norte de los $23^{\circ} \mathrm{S}$ existen además magnitudes más altas que superan los 0,55 ; en cambio al sur de los $23^{\circ} \mathrm{S}$, las magnitudes se mantienen entre los $0,4-0,5$, pero predominando los valores bajos de este rango y con algunos valores aún menores. Las cotas de la vertiente occidental de la Cordillera de la Costa (Fig. 2) y en particular del Acantilado Costero, son variables al norte de esta latitud (acantilado: 600-2.000 m s.n.m.), por lo que estas magnitudes de las integrales no serían independientes de estas cotas. Las cotas influyen en la forma de la incisión de los drenajes en el talud del Acantilado Costero que presentan distinta energía potencial en función de estas cotas. Entonces las magnitudes de las integrales hipsométricas de los drenajes menores a $100 \mathrm{~km}^{2}$ evidencian principalmente la erosión en el talud del Acantilado Costero y no de la topografía más antigua de la Cordillera de la Costa localizada en las vecindades. Al norte de los $23^{\circ} \mathrm{S}$ las incisiones son más profundas en el talud del Acantilado Costero, concentrándose en cotas altas; en cambio al sur de los $23^{\circ} \mathrm{S}$, los valles de los drenajes que descienden por el talud del Acantilado Costero son más anchos.

La forma de la curva hipsométrica para las cuencas con superficie inferior a $100 \mathrm{~km}^{2}$ es suavemente sinuosa (Fig. 13); en general, todas las curvas en el área de estudio son muy similares, pero las curvas presentes en el extremo norte son más convexas y las del extremo sur más cóncavas. Ello se corresponde con los valores de las integrales hipsométricas que

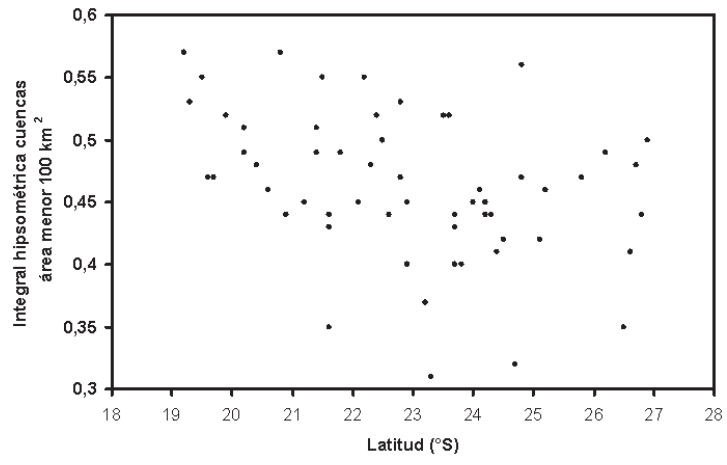

FIG. 12. Distribución de las integrales hipsométricas de área menor a $100 \mathrm{~km}^{2}$ de las cuencas versus latitud. Al norte de los $23^{\circ} \mathrm{S}$ las integrales hipsométricas tienen valores más altos que al sur, evidenciando una mayor incisión en el talud del Acantilado Costero.

están en un rango intermedio, es decir, cercano a 0,5 donde existe un equilibrio entre la componente tectónica y climática del relieve. Considerando que las cuencas de estos drenajes tienen superficie pequeña y se restringen al talud del Acantilado Costero, estas curvas evidencian el grado de madurez del paisaje asociado a este relieve. En el extremo norte los drenajes presentan una incisión en el talud del acantilado con un valle de poca superficie, en cambio en el extremo sur, los drenajes no presentan incisión, por el contrario, tienen valles más ensanchados. Esta diferencia evidencia principalmente el predominio de la componente tectónica del relieve en el norte del área de estudio y del clima, en el sur. Sin embargo, las curvas e integrales hipsométricas de los drenajes que descienden por el talud del Acantilado Costero de área menor a $100 \mathrm{~km}^{2}$, indican que este cambio es gradual. 


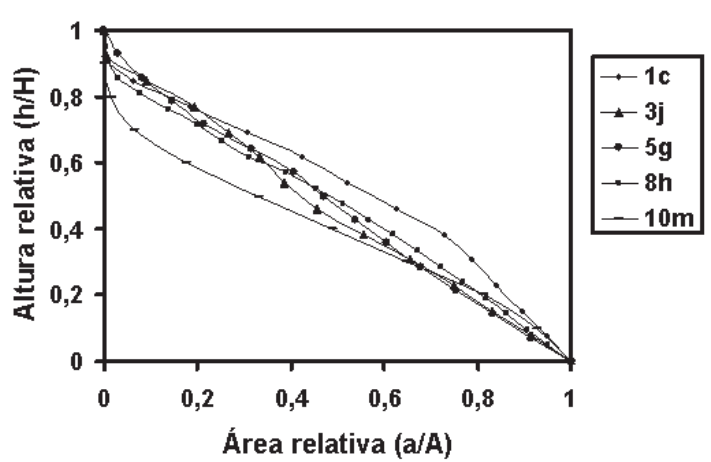

FIG. 13. Curvas hipsométricas representativas de drenajes con cuencas hidrográficas de área menor a $100 \mathrm{~km}^{2}$. La curva más al norte (1c) es convexa y la más al sur $(10 \mathrm{~m})$ es cóncava; las intermedias, rectas.

\subsection{Perfiles de thalweg}

Los perfiles longitudinales de un drenaje o perfiles de thalweg, proporcionan información sobre cambios de nivel de base del paisaje. Un perfil cóncavo representa un estado cercano al equilibrio del relieve con su nivel de base, mientras que un cambio abrupto de pendiente a lo largo del perfil o una convexidad en el mismo, puede ser el resultado de la propagación de la incisión aguas arriba por el thalweg, producto de un cambio en la posición del nivel de base. Esta perturbación en la pendiente del thalweg se denomina el 'knickpoint' (inflexión).

Para el presente estudio se realizaron perfiles longitudinales de algunas cuencas de drenaje de superficie inferior a $100 \mathrm{~km}^{2}$ que son aquellos drenajes cuyas cuencas hidrográficas se restringen al talud del Acantilado Costero. Se realizaron perfiles de thalweg de los drenajes de área menor a $100 \mathrm{~km}^{2}$ indicados en la tabla 2, de los cuales los perfiles más representativos se ilustran en la figura 14 . Los drenajes situados más al norte entre los $19,2^{\circ}$ $20,2^{\circ} \mathrm{S}$ presentan un perfil de thalweg colgado en el Acantilado Costero (e.g., drenaje 2i, Fig. 14). Estos se desarrollan solo desde la parte alta del talud del Acantilado Costero aguas arriba y exponen una muy baja incisión ( $<50 \mathrm{~m}$ de diferencia de altitud entre la línea de divisoria de aguas que se extiende paralela al thalweg y este último). Hacia el sur entre los $20,2^{\circ}-22,1^{\circ} \mathrm{S}$, los thalweg comienzan paulatinamente a incidir en el talud del Acantilado Costero (e.g., drenaje 5c, Fig. 14); un primer tramo en cotas bajas afecta el talud con una pendiente algo menor que la de éste y es separado por un 'knickpoint' del resto del drenaje aguas arriba, el que se desarrolla aún con una muy baja incisión. Entre los $22,2^{\circ}-22,5^{\circ} \mathrm{S}$, el thalweg evidencia una incisión más profunda en el talud del Acantilado Costero, y los 'knickpoints' se desarrollan en dirección de más aguas arriba que para las cuencas de más al norte (e.g., drenajes 5r y 6d, Fig. 14). A partir de este segmento en dirección hacia el sur, se verifica además un progresivo incremento de la degradación del talud del Acantilado Costero con una mayor densidad de quebradas. Entre $\operatorname{los} 22,6^{\circ}-23,7^{\circ} \mathrm{S}$, el perfil es cóncavo hacia arriba sin la presencia de 'knickpoint' (e.g., drenaje 6o, Fig. 14). Este segmento coincide con la presencia de la Península de Mejillones, y la Falla Salar del Carmen en la Cordillera de la Costa que constituye el límite oriental de las cuencas hidrográficas de mayor superficie. Entre los $24,1^{\circ}-24,2^{\circ} \mathrm{S}$, la incisión de los drenajes en el talud del Acantilado Costero es baja (similar al drenaje $2 \mathrm{i}$, Fig. 14). Más al sur, entre $\operatorname{los} 24,2^{\circ}-26,5^{\circ} \mathrm{S}$, se desarrolla un perfil de thalweg con un 'knickpoint', similar a los que se presentan entre los $22,2^{\circ}-22,5^{\circ} \mathrm{S}$ (e.g., drenajes $5 \mathrm{r}$ y $8 \mathrm{~s}$ ), que se presenta cada vez más aguas arriba al aumentar la latitud. Sin embargo, el perfil de thalweg es cóncavo hacia arriba también aguas arriba del 'knickpoint' (e.g., drenaje 8s). Los perfiles de thalweg de los drenajes situados al sur de $\operatorname{los} 26,5^{\circ} \mathrm{S}$ son todos cóncavos hacia arriba sin 'knickpoint', similares a los que se presentan en el segmento comprendido entre los 22,6 $6^{\circ}-23,7^{\circ} \mathrm{S}$ (e.g., drenaje 6o, Fig. 14). Este perfil representa un estado de equilibrio.

\section{4. Índice de sinuosidad}

El índice de sinuosidad fue definido para frentes de montaña controlados por fallas de alto ángulo para estudiar el papel relativo de los movimientos acomodados por las fallas que tienden a producir un frente recto y la erosión que tiende a formar un frente sinuoso (Bull y Mc Fadden, 1977; Keller y Pinter, 1996). Se calcula mediante la razón IS=L/LR donde IS es la sinuosidad del frente de montaña, L corresponde al perímetro de la base de la montaña medido entre dos puntos y LR es la línea recta entre estos dos puntos (Fig. 15a). Con un valor bajo de sinuosidad, el frente de montaña es recto, predominando los rasgos del paisaje de origen tectónico, mientras que, con un valor mayor, el frente es irregular, predominando los rasgos erosivos del paisaje. 
FIG. 14. Perfiles de thalweg de drenajes representativos que descienden por el Acantilado Costero. La línea negra representa el perfil de thalweg y la línea roja la topografía correspondiente al talud del Acantilado Costero. Los perfiles de thalweg son más concavos hacia el sur. Los 'knickpoints' migran hacia el este aguas arriba y en los drenajes más australes, la migración ha sido completa y el perfil de thalweg es cóncavo hacia arriba en su totalidad.
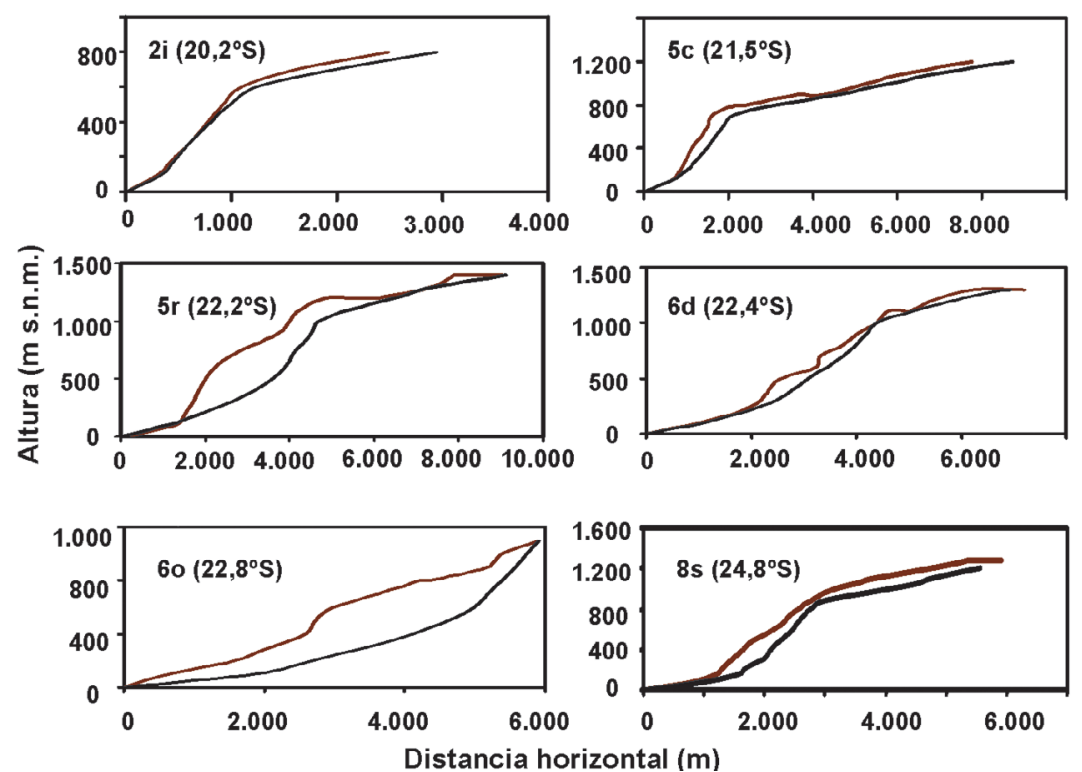

Burbank y Anderson (2001) establecen que para valores cercanos a 1 , el frente se considera activo y para valores superiores a 2, el frente tiene poca actividad de fallas y los escarpes son degradados por procesos exógenos.

El índice de sinuosidad de la base del Acantilado Costero depende de la intensidad de los procesos erosivos ligados al desarrollo de quebradas (Fig. 16). Esta intensidad está gobernada por las variaciones del nivel oceánico y por las variaciones climáticas latitudinales. Las variaciones del nivel oceánico son a su vez producto de alzamiento tectónico o de eustatismo, siendo este último factor constante a lo largo de todo el margen costero. Así, las variaciones latitudinales del índice de sinuosidad dan cuenta del efecto relativo de las variaciones latitudinales climáticas y de alzamiento tectónico. Sin embargo, este índice depende también de la acción de la abrasión marina que resulta en la existencia de rasgos del paisaje que incrementan la sinuosidad, tales como bahías o penínsulas. Para separar la sinuosidad debida al desarrollo de quebradas, de aquella producida por la abrasión marina, en este estudio se determinan el índice de sinuosidad de la base del Acantilado Costero y el índice de sinuosidad del litoral (Fig. 15b).

Sea ISBA el índice de sinuosidad de la base del Acantilado Costero, entonces: ISBA=LBA/LR, donde LBA es el perímetro de la base del acantilado y LR es la línea recta en el segmento considerado.

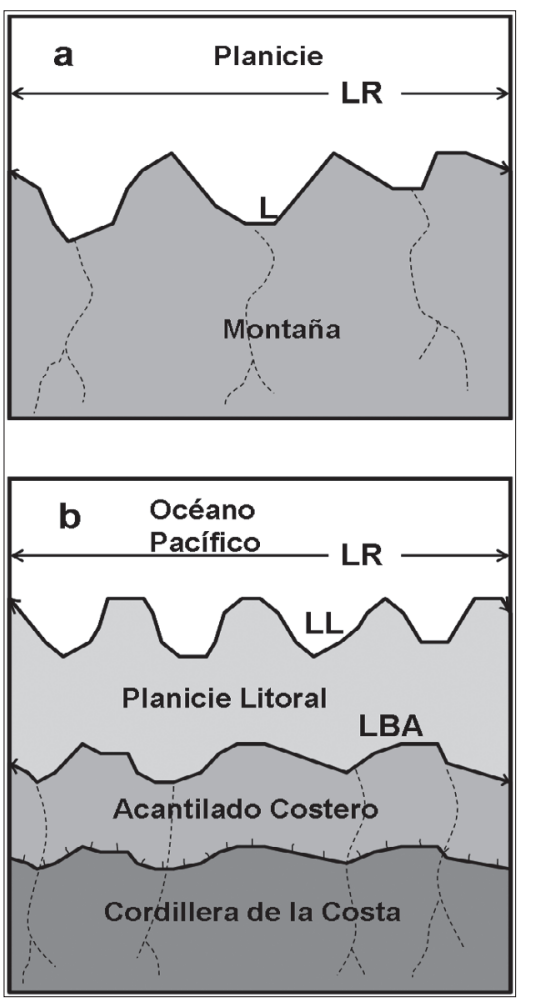

FIG. 15. Procedimiento para determinar el índice de sinuosidad. a. Cálculo del índice de sinuosidad de un frente montañoso: IS=L/LR; b. Cálculo del índice de sinuosidad de la base del Acantilado Costero: ISBA=LBA/LR y del litoral: $\mathrm{IL}=\mathrm{LL} / \mathrm{LR}$. 

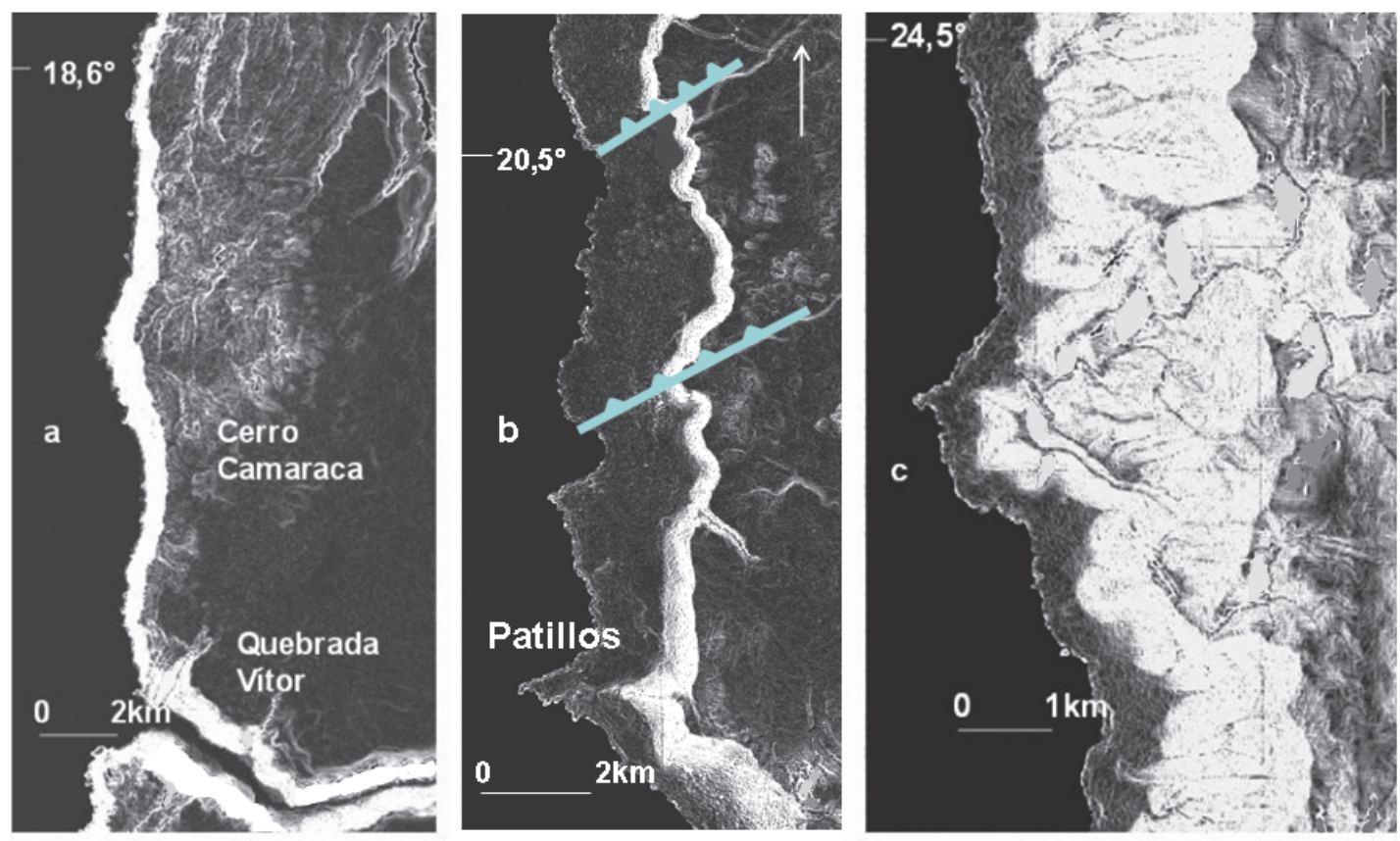

FIG. 16. Mapa de pendientes donde destaca el talud del Acantilado Costero en una tonalidad clara. a. Extremo norte de la Cordillera de la Costa, cerro Camaraca, el acantilado es activo y corta drenajes preexistentes que se formaron en una topografía antigua de la Cordillera de la Costa que está siendo erosionada; b. Sur de Iquique, se desarrolla una plataforma litoral en la base del acantilado, una quebrada desciende por el talud formando una incisión. Se ilustran dos fallas inversas que afectan la Cordillera de la Costa y plataforma de abrasión marina emergida; c. Sur de Antofagasta, la mayor densidad de quebradas por aumento de pluviosidad provoca un aumento de la sinuosidad en la base del Acantilado Costero. Donde el acantilado es inactivo, el trazado del litoral y base del acantilado son subparalelos.

Sea ISL el índice de sinuosidad del litoral, entonces:

$$
\mathrm{ISL}=\mathrm{LL} / \mathrm{LR}
$$

donde LL es el perímetro del litoral y LR es la línea recta en el segmento considerado.

La diferencia aritmética entre ISBA e ISL refleja la sinuosidad de la base del Acantilado Costero restando de esta, aquella de gran longitud de onda asociada a los rasgos del paisaje producidos por la acción de la erosión marina. Un valor cercano a cero en esta diferencia significa que la línea de costa y la base del Acantilado Costero son paralelas. Tomando en consideración que las quebradas desaguan directamente sobre la plataforma litoral, un valor cercano a cero refleja también la baja incisión de quebradas en el talud del Acantilado Costero. Por el contrario, una magnitud de la diferencia mayor a cero significa que la acción de quebradas en la degradación del relieve tiene mayor importancia.
En el cálculo de este índice se ha eliminado la región costera donde se ubica la Península de Mejillones $\left(23^{\circ}-23,4^{\circ} \mathrm{S}\right)$, dado que es una singularidad topográfica que influye en los procesos de erosión litoral y no existe correspondencia entre la línea del litoral y la base del Acantilado Costero.

Los resultados de la determinación del índice de sinuosidad de la base del Acantilado Costero y del litoral, se ilustran en la figura 17 y tabla 3 . En la zona más al norte del área de estudio entre los $18,5^{\circ}$ y $21^{\circ} \mathrm{S}$, la diferencia aritmética entre ISBA e ISL es cero. Esto significa que el Acantilado Costero se encuentra poco afectado por el desarrollo de quebradas. Efectivamente, en este segmento el Acantilado Costero se encuentra mayoritariamente activo (la base del acantilado coincide con el litoral, Fig. 16a) y las quebradas tienen casi nula participación en su degradación. Sin embargo, existe un valor negativo de $-0,04\left(19,3^{\circ}-19,6^{\circ} \mathrm{S}\right)$ que coincide con una zona de desarrollo local de una plataforma litoral en la base del Acantilado Costero. Esta plataforma litoral se 
ubica en la zona donde las fallas inversas de orientación E-O intersectan perpendicularmente el litoral entre la desembocadura de la quebrada Camarones y Pisagua (Figs. 1, 5a). Un leve incremento de la diferencia hacia el sur $\left(20,4^{\circ}-21,9^{\circ} \mathrm{S}\right)$ evidencia un escaso desarrollo de quebradas en el talud del Acantilado Costero. La plataforma litoral tiene un ancho variable, supera los $2 \mathrm{~km}$ entre Iquique y Patillos (Figs. 1, 5b y 16b), más al sur está reducida a la mínima expresión hasta la desembocadura del río Loa donde vuelve a adquirir un ancho cercano a $2 \mathrm{~km}$. En este segmento, la cornisa del Acantilado Costero está muy bien preservada (Fig. 16b) y el litoral es subparalelo a la base del Acantilado Costero. A partir de los $22^{\circ} \mathrm{S}$ hasta los $22,8^{\circ} \mathrm{S}$, la diferencia se incrementa abruptamente en un orden de magnitud, alcanzando valores de hasta 0,38 . Este incremento se debe a un mayor desarrollo de quebradas a lo largo del talud del Acantilado Costero, desde las cuales desaguan grandes abanicos aluviales que pueden superar los $200 \mathrm{~m}$ de ancho y $20 \mathrm{~m}$ de potencia de la cobertura detrítica que se deposita sobre la plataforma de abrasión marina. En la parte norte de este segmento, la plataforma de abrasión marina tiene un ancho inferior a $500 \mathrm{~m}$ y los abanicos aluviales la cubren por completo, siendo truncados en su frente por el mar (Fig. 7). La altura de este frente truncado puede superar los $20 \mathrm{~m}$ cerca de Tocopilla $\left(22^{\circ} \mathrm{S}\right)$.
Una incisión se genera en estos abanicos debido a un flujo aluvional posterior que baja por el frente del abanico truncado por el mar, se produce un descenso de nivel de base con la consecuente incisión (Fig. 7 , drenaje 2). Hacia la parte sur este segmento $\left(22,8^{\circ} \mathrm{S}\right)$, la plataforma de abrasión marina es más ancha, con más de $1 \mathrm{~km}$ de modo que los abanicos aluviales no alcanzan a llegar al litoral.

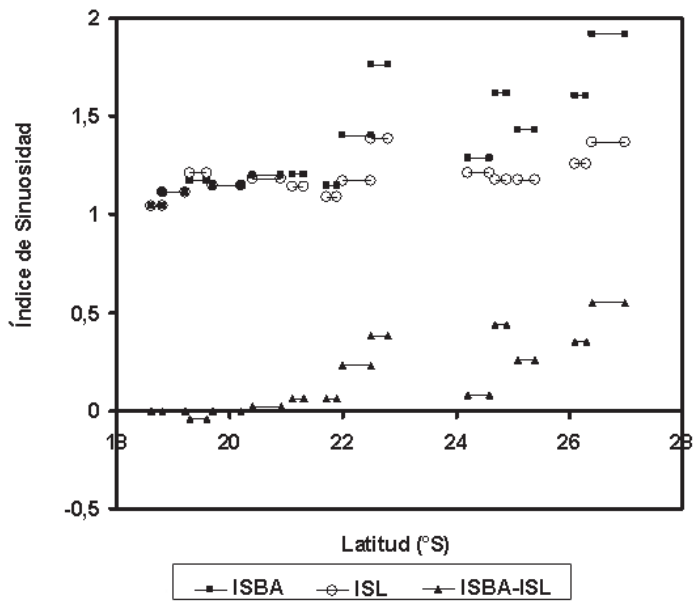

FIG. 17. Distribución del índice de sinuosidad versus latitud. Los cambios más significativos ocurren aproximadamente a $\operatorname{los} 22^{\circ}, 24^{\circ}$ y $26^{\circ}$.

TABLA 3. ÍNDICE DE SINUOSIDAD.

\begin{tabular}{ccccccc}
\hline $\begin{array}{c}\text { Segmento } \\
\mathbf{(} \mathbf{S})\end{array}$ & $\begin{array}{c}\mathbf{L B A} \\
\mathbf{( k m )}\end{array}$ & $\begin{array}{c}\mathbf{L L} \\
\mathbf{( k m})\end{array}$ & $\begin{array}{c}\mathbf{L R} \\
\mathbf{( k m )}\end{array}$ & ISBA & ISL & ISBA-ISL \\
\hline $18,6-18,8$ & 24,5 & 24,5 & 23,5 & 1,04 & 1,04 & 0,00 \\
$18,8-19,2$ & 48,9 & 48,9 & 44 & 1,11 & 1,11 & 0,00 \\
$19,3-19,6$ & 43,8 & 45,2 & 37,4 & 1,17 & 1,21 & $-0,04$ \\
$19,7-20,2$ & 67,3 & 67,3 & 58,7 & 1,15 & 1,15 & 0,00 \\
$20,4-20,9$ & 61,6 & 60,7 & 51,3 & 1,20 & 1,18 & 0,02 \\
$21,1-21,3$ & 37,8 & 35,9 & 31,4 & 1,20 & 1,14 & 0,06 \\
$21,7-21,9$ & 30,8 & 29,3 & 26,9 & 1,14 & 1,09 & 0,06 \\
$22-22,5$ & 82,1 & 68,7 & 58,6 & 1,40 & 1,17 & 0,23 \\
$22,5-22,8$ & 57,2 & 45 & 32,5 & 1,76 & 1,38 & 0,38 \\
$24,2-24,6$ & 52,4 & 49,3 & 40,7 & 1,29 & 1,21 & 0,08 \\
$24,7-24,9$ & 34,1 & 24,8 & 21,1 & 1,62 & 1,18 & 0,44 \\
$25,1-25,4$ & 42 & 34,4 & 29,3 & 1,43 & 1,17 & 0,26 \\
$26,1-26,3$ & 41,3 & 32,3 & 25,7 & 1,61 & 1,26 & 0,35 \\
$26,4-27$ & 103,2 & 73,5 & 53,8 & 1,92 & 1,37 & 0,55
\end{tabular}

LBA: perímetro de la base del acantilado; LL: perímetro del litoral; LR: línea recta del segmento considerado; ISBA: índice sinuosidad de la base del acantilado referida a la línea recta; ISL: índice sinuosidad del litoral. 
Entre los $24^{\circ}-24,6^{\circ} \mathrm{S}$ la diferencia entre ISBA e ISL disminuye a 0,08 , coincidiendo con un tramo activo del Acantilado Costero. En este tramo la línea litoral presenta muchas bahías que determinan que el ISL tenga un valor alto de 1,21. La vertiente del acantilado también se encuentra fuertemente afectada por quebradas, por lo que el valor de ISBA también es grande y mayor que ISL. Entre $24,7^{\circ}-27^{\circ} \mathrm{S}$, la diferencia entre estos índices alcanza valores máximos de hasta 0,55 . En este segmento destaca el aumento de ISBA; en efecto, al sur de los $26,1^{\circ} \mathrm{S}$, este índice tiene valores superiores a 1,61. Estos valores altos reflejan el gran desarrollo de quebradas y la fuerte erosión que ha experimentado la base del Acantilado Costero (Fig. 16c). En este segmento también se desarrollan abanicos aluviales coalescentes en las desembocaduras de las quebradas que se depositan sobre la plataforma de abrasión marina. La cobertura detrítica fluctúa entre 10-20 m.

Las mayores diferencias en los valores de ISBAISL ocurren al norte y sur de los $22^{\circ} \mathrm{S}$; entre los $24,6^{\circ}-24,7^{\circ} \mathrm{S}$ y entre $26,3-26,4^{\circ} \mathrm{S}$. En el primer caso esa diferencia se correlaciona con la casi ausencia de quebradas en el talud del Acantilado Costero y la preservación de la cornisa al norte de los $22^{\circ} \mathrm{S}$. Por el contrario, desde esta latitud y hasta el extremo sur del área del estudio, el talud del Acantilado Costero se encuentra fuertemente afectado por la presencia de quebradas. En el segundo caso, se tiene que en el segmento ubicado al norte de los $24,6^{\circ} \mathrm{S}$, el Acantilado Costero se encuentra activo y su base coincide con el litoral, no obstante el ISBA entre este segmento de Acantilado Activo $\left(24,2^{\circ}-24,6^{\circ} \mathrm{S}\right)$ es sensiblemente mayor que los otros segmentos ubicados en el extremo norte del área de estudio $\left(18,6^{\circ}-19,2^{\circ} \mathrm{S}\right)$ donde el Acantilado Costero también se encuentra activo (Tabla 3 ), y que tienen un ISBAISL también bajo. De este modo el ISBA refleja el mayor desarrollo de quebradas en este segmento e ISBA-ISL, la coincidencia entre el litoral y la base del Acantilado Costero debido al hecho de ser un acantilado activo. En el tercer caso, entre los $26,3^{\circ}-$ $26,4^{\circ} \mathrm{S}$, la diferencia ISBA-ISL es grande al norte y sur de esta latitud evidenciando un gran desarrollo de quebradas, pero esta diferencia es mucho mayor al sur donde no existe ninguna preservación de la cornisa del Acantilado Costero y existe una mayor densidad de quebradas en el talud del acantilado. Esto coincide con un aumento en la pluviosidad en un orden de magnitud que supera los $10 \mathrm{~mm} / \mathrm{a}$ al sur de los $26^{\circ} \mathrm{S}$ (Tabla 1). Otro cambio se genera al norte y sur de la península de Mejillones $\left(23^{\circ}-23,6^{\circ} \mathrm{S}\right)$. En el segmento ubicado al norte esta singularidad topográfica tiene mayor ISBA y mayor diferencia ISBA-ISL. Ello evidencia una mayor sinuosidad de la base del Acantilado Costero y del litoral al norte de la península de Mejillones que al sur. La diferencia que presenta el Acantilado Costero en los segmentos inmediatamente al norte y sur de la península de Mejillones considerados para determinar el índice de sinuosidad, es que al norte el acantilado se encuentra inactivo, mientras que al sur se encuentra activo. De este modo, si se omite el segmento donde el Acantilado Costero se encuentra activo $\left(24,2^{\circ}-24,6^{\circ} \mathrm{S}\right)$, que es una singularidad en un contexto general regional donde el Acantilado Costero se encuentra inactivo, y se omite también la península de Mejillones, que es otra singularidad topográfica, los valores de los índices ISBA e ISBA-ISL en el segmento ubicado al norte de estas dos singularidades $\left(22,5^{\circ}-22,8^{\circ} \mathrm{S}\right)$ y del segmento ubicado inmediatamente al sur $\left(24,7^{\circ}-24,6^{\circ} \mathrm{S}\right)$ son similares. Ello se corresponde con la similar pluviosidad que se presenta entre los $22-25^{\circ} \mathrm{S}$ (Tabla 1 ) y las diferencias en los índices reflejan singularidades topográficas más que procesos erosivos ligados al clima reflejados en el talud del Acantilado Costero entre los $22,8^{\circ}-24,6^{\circ} \mathrm{S}$.

\section{Discusión}

\subsection{Balance de la tectónica y el clima}

El análisis geomorfológico del relieve de la Cordillera de la Costa y en especial de su vertiente occidental, el Acantilado Costero permite ponderar los efectos de la tectónica y clima en su configuración actual. Destaca en forma regional la existencia de un paleorrelieve que domina la parte alta de la Cordillera de la Costa y que se preserva en forma espectacular en el extremo norte del área de estudio. Los rasgos morfológicos originales de este paleorrelieve consisten en paleosuperficies de erosión regional y extensos pediplanos (e.g., pediplano de Tarapacá) labrados sobre rocas ígneas mesozoicas, principalmente al norte de los $25^{\circ} \mathrm{S}$ (Figs. 7 y 8). Mortimer (1973) señala que el alzamiento de la Cordillera de la Costa con respecto a la Depresión Intermedia en el norte de Chile, ocurrió en una fase temprana de la evolución del paisaje y con posterioridad a este alzamiento, la Cordillera de la Costa fue afectada por fallas. La 
topografía antigua de la Cordillera de la Costa es la que condiciona los escalonamientos de las cotas medias que se observan en los perfiles topográficos (Fig. 2). Los principales sistemas estructurales de la Cordillera de la Costa afectan a este paleorrelieve, incluyendo el SFA, fallas inversas de orientación E-O y fallas de rumbo NNO-SSE. Ello indica que estos escalonamientos latitudinales de las cotas medias de la Cordillera de la Costa, se formaron por procesos tectónicos desarrollados con anterioridad a la actividad de estas fallas. Dunai et al. (2005) determinaron una edad oligocena-miocena para paleosuperficies en la Cordillera de la Costa en el extremo norte del área de estudio. Las bajas tasas de erosión presentes en la Cordillera de la Costa, inferiores a $0,02 \mathrm{~mm} / \mathrm{a}$ (Riquelme et al., 2008), permiten una extraordinaria preservación de este paleorrelieve de edad premiocena de la Cordillera de la Costa, así como de los escarpes de las fallas que afectaron a este paleorrelieve con posterioridad sean del SFA, fallas inversas de rumbo E-O y fallas de rumbo NNO-SSE (Allmendinger et al., 2005; Carrizo et al., 2008a). Los escarpes de las fallas más importantes que contribuyen a la topografía de la Cordillera de la Costa, son aquellos de la Falla Paposo del SFA (Figs. 1, 4 y 5c), y las fallas inversas E-O presentes entre la desembocadura de la quebrada Camarones y Pisagua $\left(19,2^{\circ}-19,5^{\circ} \mathrm{S}\right.$, Figs. 1, 4 y 5a). Otras fallas limitan cordones montañosos al interior de la Cordillera de la Costa, constituyendo frentes rectos de montaña. En esta categoría se incluyen muchas trazas del SFA, considerando las fallas Salar Grande y Salar del Carmen (Figs. 1, 4 y 8), y fallas de rumbo NNO-SSE (Figs. 1, 4, 5 b y 8a). La mayoría de las fallas inversas de orientación E-O no contribuyen significativamente a la topografía de la Cordillera de la Costa, con excepción de las mencionadas anteriormente. La topografía asociada a la actividad de estas fallas son superficies antiformes que constituyen colinas elongadas según el rumbo de la traza de la falla, destacando aquellas del sistema Chuculay al este del Salar Grande (Allmendinger et al., 2005; González et al., 2003).

El análisis de los modelos de elevación digitales del terreno e imágenes satelitales (Figs. 7, 8 y 16), muestran que el paleorrelieve preservado en la parte alta de la Cordillera de la Costa se encuentra truncado por el proceso de erosión ligado a la construcción del Acantilado Costero. Evidencias de esto lo constituyen los drenajes que escurren tanto hacia el este como hacia el oeste y que están truncados en la parte alta del Acantilado Costero (Figs. 8a, 16a y Tabla 2). Estos drenajes se preservan principalmente en la parte norte del área de estudio (al norte de los $22^{\circ} \mathrm{S}$ ). Niemeyer et al. (1996) destacan la existencia de gravas colgadas en la parte alta del Acantilado Costero, lo cual es testimonio de la longevidad del proceso de erosión que ha afectado a este paleorrelieve. Lo anterior indica que el Acantilado Costero es un rasgo erosivo más joven de la Cordillera de la Costa el cual trunca, además, las fallas de los tres sistemas estructurales presentes en la Cordillera de la Costa (Fig. 5). De esta forma, la altura del Acantilado Costero está determinada por la altura del relieve de la Cordillera de la Costa que trunca.

Las edades más jóvenes obtenidas en la paleotopografía truncada por el proceso de construcción del Acantilado Costero, están dadas por horizontes de cenizas volcánicas intercaladas en gravas colgadas en el sector de Barranco Alto $\left(20,6^{\circ} \mathrm{S}\right)$ y Punta de Lobos $\left(21^{\circ} \mathrm{S}\right)$ y que dan edades de entre 6 a 5,5 Ma (González et al., 2003; Allmendinger et al., 2005). Marquardt et al. (2005) dataron un horizonte de cenizas expuesto en un espolón, en la plataforma de abrasión marina más alta de la base del Acantilado Costero en la Punta Yayes $\left(22,8^{\circ} \mathrm{S}\right)$ entre Hornitos y Michilla, obteniendo 2,04 Ma en sanidina y 2,61 Ma en biotita. Con estos antecedentes se puede concluir que el Acantilado Costero tiene una edad que fluctúa entre 6 y 2 Ma.

En síntesis, existe un paleorrelieve de edad oligo-miocena de la Cordillera de la Costa, el cual ha sido afectado por fallas durante el Neógeno. Esta topografía fue y está siendo truncada por el proceso de erosión ligado a la formación del gran Acantilado Costero (abrasión marina) que es un rasgo más joven del relieve de la Cordillera de la Costa. Las zonas donde la abrasión marina continúa erosionando la base del Acantilado Costero y truncando la topografía del borde occidental de la Cordillera de la Costa, son aquellas donde el acantilado se encuentra activo, es decir, en contacto directo con el mar, existiendo dos segmentos: 1. entre Arica e Iquique $\left(18,5^{\circ}-20,3^{\circ} \mathrm{S}\right.$, Figs. 5a y 16a), excepto el tramo comprendido entre la desembocadura de la quebrada Camarones y Pisagua $\left(19,2^{\circ}-19,5^{\circ} \mathrm{S}\right.$, Fig. 5a) y 2. entre Caleta Coloso y Caleta El Cobre $\left(24^{\circ}-24,6^{\circ} \mathrm{S}\right.$, Fig. 5b). Los demás segmentos del Acantilado Costero están aislados de la abrasión marina debido a la presencia de la plataforma de abrasión marina emergida, es decir, en estas zonas existe una evidencia de alzamiento 
litoral durante el Pleistoceno. Este alzamiento es de carácter regional y modificado localmente por actividad de fallas.

Con esta configuración del relieve del borde costero del norte de Chile, se tiene que los índices geomorfológicos considerados en el presente estudio entregan información particular sobre el predominio de los procesos tectónicos y climáticos antes y después de la formación del Acantilado Costero. Los índices que consideran la topografía antigua de la Cordillera de la Costa formada con anterioridad al Acantilado Costero y el acantilado mismo, son incisión y las curvas e integrales hipsométricas de los drenajes que descienden por el talud del Acantilado Costero con cuencas hidrográficas de superficie mayor a $100 \mathrm{~km}^{2}$. Por el contrario, los índices que ponderan la componente tectónica y climática del relieve constituido por el Acantilado Costero después de la formación del talud original son índice de sinuosidad, perfiles de thalweg y curvas e integrales hipsométricas de los drenajes que descienden por el talud del Acantilado Costero con cuencas hidrográficas de superficie menor a $100 \mathrm{~km}^{2}$. Realizar una separación entre índices que consideren procesos antes y después de la formación del Acantilado Costero, permite hacer una separación temporal de estos procesos y además precisar sobre el origen del Acantilado Costero.

El análisis de los índices que incluyen la topografía antigua de la Cordillera de la Costa evidencia una incisión ligada a la tectónica y la erosión. La incisión ligada a la tectónica es aquella que se presenta en las trazas de las fallas y delimitan bloques que ascienden y descienden ya sea por la presencia de escarpes o frentes de montañas rectilíneos (Fig. 5). Además, escarpes grandes del SFA, especialmente la Falla Paposo (Fig. 5c), provocan una mayor incisión de los drenajes en el bloque alzado al oeste de esta falla. Los escarpes de estas fallas limitan las cuencas hidrográficas de estos drenajes por el este (Figs. 5c y 8c). Los drenajes que vienen desde el este al llegar a estos escarpes de falla son desviados al norte o sur según la pendiente topográfica regional (Fig. 5c). Las cuencas hidrográficas grandes están limitadas por cordones montañosos, la mayoría controlados tectónicamente (Fig. 8) y debido a esta superficie mayor, los drenajes que descienden por el Acantilado Costero de estas cuencas tienen un mayor poder erosivo que aquellos drenajes con cuencas hidrográficas ubicadas entre estas cuencas grandes, las que tienen una menor superficie. Las incisiones ligadas al clima, se hacen manifiestas al sur de los $26^{\circ} \mathrm{S}$ donde los drenajes que atraviesan transversalmente la Cordillera de la Costa cortan inclusive los escarpes de falla del SFA (Fig. 4), y debido a la gran densidad de incisiones que evidencia una mayor jerarquía del drenaje, los rasgos originales del relieve como trazas de fallas se distinguen con dificultad al sur de los $26^{\circ} \mathrm{S}$. Este cambio coincide con el aumento de las precipitaciones al sur de los $26^{\circ} \mathrm{S}$ (Tabla 1). Como se considera topografía antigua de la Cordillera de la Costa, es posible que esta latitud marque un límite importante del avance al norte de frentes de mal tiempo, sean por un debilitamiento del anticiclón del Pacífico, fenómenos El Niño u otros que se extendieron hasta el Plioceno por lo menos.

Las curvas hipsométricas de los drenajes de cuencas mayores a $100 \mathrm{~km}^{2}$ evidencian, además, el rejuvenecimiento del paisaje el cual es respuesta del truncamiento del relieve antiguo de la Cordillera de la Costa por el retroceso al este del talud del Acantilado Costero (Fig. 11). La concavidad de las curvas en el segmento que comprende el relieve antiguo indica que en este relieve predominan los procesos erosivos. El rejuvenecimiento del relieve evidenciado por las incisiones de los drenajes que descienden por el Acantilado Costero, se debe al descenso del nivel de base desde peniplanicies localizadas en el relieve antiguo de la Cordillera de la Costa que se encuentran a una cota cercana a $1.000 \mathrm{~m}$ s.n.m., hasta el nivel del mar (Fig. 8). Estas incisiones se propagan desde el talud del acantilado hacia el este. Este proceso explica también las grandes incisiones transversales de los drenajes que vienen desde la Precordillera (quebradas entre Arica e Iquique y río Loa) que eran bloqueados en su paso al mar por esta paleotopografía formando cuencas lacustres (e.g., paleolago Soledad en el río Loa que ocupó la superficie de los actuales salares de Llamara y Grande, figura 1), hasta que por erosión de la paleotopografía, estos drenajes lograron llegar al mar generándose un descenso del nivel de base (Quezada y Cerda, 2003). El mayor caudal de agua de estos drenajes durante períodos pluviales que ocurren en la Precordillera (principalmente durante el verano), explica la mayor incisión en la topografía tanto en profundidad como en el ancho de los valles (Figs. 4 y 5a). Las magnitudes de las integrales hipsométricas de los drenajes de cuencas mayores a $100 \mathrm{~km}^{2}$ son variables destacando las mayores entre Paposo y Taltal $\left(25^{\circ}-25,5^{\circ} \mathrm{S}\right)$ (Fig. 10). En esta zona no existe ninguna traza de falla asociada al SFA y se localiza entre los segmentos Paposo y Salado de este 
sistema de fallas, permitiendo que las incisiones de los drenajes en la Cordillera de la Costa avancen sin barreras topográficas desde el litoral hacia el este. De este modo, los drenajes que descienden por el Acantilado Costero se extienden hacia el este por más de $20 \mathrm{~km}$ hacia el interior de la Cordillera de la Costa produciendo una incisión profunda en el relieve debido al descenso del nivel de base. Este proceso es válido también para algunos drenajes situados al norte de los $23^{\circ} \mathrm{S}$ (Fig. 10) en los cuales la incisión penetra varios kilómetros al este del Acantilado Costero afectando la paleotopografía de la Cordillera de la Costa, pero en esta zona siempre la cuenca hidrográfica es limitada al este por serranías controladas tectónicamente (Fig. 8b).

Con respecto a aquellos índices geomorfológicos que se restringen al Acantilado Costero, el que presenta mayores variaciones es el índice de sinuosidad (Fig. 17). El cambio más notable ocurre alrededor de los $22^{\circ} \mathrm{S}$. La magnitud del índice de sinuosidad de la base del acantilado (ISBA) es menor al norte que al sur de esta latitud. La magnitud del índice de sinuosidad del litoral (ISL) al norte y sur de los $22^{\circ} \mathrm{S}$ es similar y la magnitud de la diferencia ISBA-ISL es menor al sur de los $22^{\circ} \mathrm{S}$ que al norte. Ello indica que la abrasión marina es un factor constante al norte y sur de esta latitud y en general, en toda el área de estudio; en cambio, existe una variación importante en los índices que reflejan la erosión subaérea del talud del Acantilado Costero. Este cambio corresponde a la casi ausencia de quebradas que descienden por el talud del Acantilado Costero al norte de los $22^{\circ} \mathrm{S}$ con una extraordinaria preservación de la cornisa (Fig. 16b), en contraste, al sur de los $22^{\circ} \mathrm{S}$ existe un gran desarrollo de quebradas que afectan el talud del Acantilado Costero provocando un trazado más sinuoso. Considerando que la litología de la Cordillera de la Costa es similar al norte y sur de esta latitud, este cambio en la morfología del Acantilado Costero es consecuencia del factor climático indicando que al norte de los $22^{\circ} \mathrm{S}$ existen pocas perturbaciones meteorológicas anómalas o si existen son de baja intensidad, mientras que al sur estas perturbaciones extraordinarias son más frecuentes. Debido a que el Acantilado Costero es un rasgo más joven del relieve del borde costero y su construcción habría finalizado ca. $2 \mathrm{Ma}$ (segmentos inactivos), y que los depósitos aluvionales cubren las terrazas marinas pleistocenas, la degradación del talud del Acantilado Costero sería consecuencia de procesos climáticos del Pleistoceno y Holoceno. Al respecto, Vargas et al. (2007) determinaron relaciones entre episodios El Niño y episodios aluvionales ocurridos en el Acantilado Costero durante el Pleistoceno (20-11 ka) y Holoceno, particularmente en la zona de Antofagasta $\left(23,7^{\circ} \mathrm{S}\right)$ y la quebrada Guanillos $\left(22^{\circ} \mathrm{S}\right)$. Por otra parte, las magnitudes máximas de ISBA e ISBA-ISL se presentan al sur de los $26,4^{\circ} \mathrm{S}$ indicando la gran sinuosidad del trazado del Acantilado Costero que también se correlaciona con el aumento de pluviosidad al sur de los $26^{\circ} \mathrm{S}$. El índice de sinuosidad refleja también los segmentos donde el Acantilado Costero se encuentra activo, en el caso donde ISBA-ISL $=0$ en el extremo norte del área de estudio, y entre los $24,2^{\circ}-24,6^{\circ} \mathrm{S}$, donde este valor es bajo entre dos segmentos adyacentes. En estos segmentos, la abrasión marina es el proceso que domina la erosión del Acantilado Costero. El hecho de que existan segmentos donde el acantilado se encuentre activo e inactivo puede estar controlado por la tectónica regional, particularmente la ocurrencia de terremotos de subducción (Quezada et al., 2005).

El índice de sinuosidad refleja también la tectónica local, particularmente entre la desembocadura de la quebrada Camarones y Pisagua (Figs. 1, 5a). En ese segmento, ISBA-ISL tiene un valor negativo (Tabla 3). Ello indica que el litoral tiene mayor sinuosidad que la base del Acantilado Costero. Esto se explica por la presencia las trazas inversas con rumbo E-O que son perpendiculares al litoral, el cual tiene una orientación regional N-S. De este modo, producto de un alzamiento local asociado a la actividad de estas fallas, se genera una sinuosidad litoral mayor muy localizada cuando el escarpe de falla intersecta al litoral.

Las fallas inversas presentes entre la desembocadura de la quebrada Camarones y Pisagua son las que tienen los escarpes más grandes evidenciando su actividad, la cual genera un alzamiento local que produce la emersión de la plataforma de abrasión marina. Este alzamiento local condiciona el hecho de que este segmento posee un acantilado inactivo, en cambio en los segmentos adyacentes ubicados al norte y sur que no tienen estas fallas, el Acantilado Costero se encuentra activo.

El segmento donde el Acantilado Costero se encuentra activo que se presenta entre $24,2^{\circ}-24,6^{\circ} \mathrm{S}$ puede explicarse por la litología. En efecto, en ese segmento se observan relictos de plataforma de abrasión marina y terrazas marinas emergidas muy erosionadas lo cual evidencia alzamiento. Este 
segmento se encuentra al sur de Antofagasta donde las rocas que afloran en el talud del Acantilado Costero son principalmente intrusivas (dioritas, gabros, monzodioritas y granodioritas), en cambio al norte de Antofagasta predominan las andesitas. No obstante lo anterior, las magnitudes de los índices de sinuosidad entre los $22^{\circ}-22,5^{\circ} \mathrm{S}$ y $24,7^{\circ}-24,9^{\circ} \mathrm{S}$ son similares (Tabla 3, Fig. 17). Estos dos segmentos poseen características fisiográficas similares: acantilado inactivo con una plataforma de abrasión marina que se ensancha hacia el sur y cubierta por abanicos aluviales, y además poseen una pluviosidad similar (Tabla 1). La diferencia es que en el primer segmento, las rocas que predominan en el Acantilado Costero son andesitas, mientras que en el segundo son intrusivas. De este modo, el factor litológico en el Acantilado Costero no es sensible a los procesos erosivos ligados al clima pero sí a la abrasión marina.

Los perfiles de thalweg y las curvas hipsométricas de los drenajes que descienden por el talud del Acantilado Costero con cuencas hidrográficas de superficie menor a $100 \mathrm{~km}^{2}$ muestran un contraste en los extremos norte y sur del área de estudio. Estos índices evidencian que en el extremo norte del área de estudio los drenajes presentan una incisión en el talud del Acantilado Costero, en cambio en el sur los drenajes presentan valles ensanchados. Ello es consecuencia de la mayor pluviosidad en el sur del área de estudio y, como estos drenajes se formaron después del talud del Acantilado Costero, estos índices señalan procesos climáticos ocurridos después de los $2 \mathrm{Ma}$.

\subsection{Origen del Acantilado Costero}

El presente estudio permite precisar además el origen del gran Acantilado Costero. Se trata de un relieve erosivo cuyo talud se habría formado entre los 6-2 Ma. Considerando que en una etapa inicial de su formación este acantilado debió ser activo, es decir, su base estuvo en contacto directo con el mar, debió tener una morfología similar a la que actualmente se presenta en el extremo norte del área de estudio, es decir, al norte de Iquique (con excepción del segmento comprendido entre la desembocadura de las quebradas Camarones y Pisagua).

Estudios realizados en cuencas marinas neógenas en el litoral de Chile entre los $23^{\circ}-30^{\circ} \mathrm{S}$ (Achurra,
2004; Le Roux et al., 2005a; Le Roux et al., 2005b; Clift y Hartley, 2007), evidencian que ocurrió una subsidencia litoral regional en el norte de Chile con anterioridad a los $2 \mathrm{Ma}$, instante en que comienza un alzamiento litoral (al sur de Iquique) que se desarrolla hasta el presente. La edad $\sim 2$ Ma es consistente con aquella determinada por Marquardt et al. (2005) en un horizonte de cenizas en la Punta Yayes $\left(22,8^{\circ} \mathrm{S}\right)$ depositada sobre el nivel más alto de la plataforma emergida en la base del Acantilado Costero que señala el comienzo de su emersión. Entonces, a los $\sim 2 \mathrm{Ma}$ ocurre una transición entre una subsidencia litoral y un alzamiento litoral regional en el norte de Chile al sur de Iquique. Esta subsidencia litoral en el norte de Chile que ocurrió con anterioridad a los 2 Ma, sería la responsable de la generación del talud original del Acantilado Costero. Estos argumentos favorecen la hipótesis de Mortimer y Saric (1972); Mortimer y Saric (1975) y Mortimer (1980), que postularon que el Acantilado Costero se habría formado durante un proceso de subsidencia litoral. Mortimer (1980) estableció además que durante el Neógeno se produjo el basculamiento hacia el oeste del antearco en el norte de Chile con un alzamiento en la zona andina (Precordillera y Cordillera Occidental) y una subsidencia en la zona litoral que formó el Acantilado Costero. En un sondaje realizado en la planicie litoral de Arica, Karzulovic (1968) ${ }^{1}$ encontró rocas continentales miocenas a $300 \mathrm{~m}$ bajo el nivel del mar. Estas rocas se extienden desde la Precordillera a una altura cercana a $1,5 \mathrm{~km}$ y tienen un manteo menor a $3^{\circ}$ hacia el oeste, de modo que estas rocas en Arica y más al oeste de la línea litoral están bajo el nivel de mar evidenciando el basculamiento al oeste del antearco que involucra alzamiento en la zona de la Precordillera y subsidencia litoral. Trabajos más recientes (Wörner et al., 2002; Farías et al., 2005 y Riquelme et al., 2007) demostraron que existe un basculamiento hacia el oeste del antearco en el norte de Chile durante el Neógeno que tuvo una importante contribución en el alzamiento andino, particularmente en la Precordillera, más que la actividad de fallas inversas de vergencia al oeste que tuvieron poca actividad durante el Plioceno. Las conclusiones de los trabajos anteriores (Karzulovic, 1968; Achurra, 2004; Le Roux et al., 2005a, b; Clift y Hartley, 2007; Wörner et al., 2002; Farías et al., 2005; Riquelme et al., 2007), confirman el planteamiento de Mortimer

\footnotetext{
${ }^{1}$ Karzulovic, J. 1968. Estudio hidrogeológico de la Región de Arica, Provincia de Tarapacá. Universidad de Chile (Inédito): 129 p. Santiago.
} 
(1980) de un basculamiento al oeste del antearco que involucra subsidencia litoral y alzamiento andino (Precordillera y Cordillera Occidental) que ocurrió durante el Neógeno, particularmente durante el Plioceno. Esta subsidencia litoral debió ser moderada para permitir que la abrasión marina erosionara el relieve preexistente de la Cordillera de la Costa, formando el Acantilado Costero que retrocedió al este hasta $c a .2 \mathrm{Ma}$ al sur de Iquique, mientras que al norte de Iquique, la presencia de un Acantilado Costero mayoritariamente activo, indica que la subsidencia litoral puede continuar en esa zona. La continuación de la subsidencia litoral entre Arica e Iquique puede ser explicada por constituir una zona de subsidencia cosísmica (Quezada et al., 2005) al diverger hacia el norte de Iquique la línea del litoral con la fosa. Esta mayor distancia litoral-fosa que condiciona una subsidencia cosísmica puede ser debida al mayor retroceso neógeno del litoral entre Arica e Iquique $\left(18,5^{\circ}-20,3^{\circ} \mathrm{S}\right)$ que explica, además, la disminución progresiva del ancho de la Cordillera de la Costa al norte de Iquique (Figs. 1, 4 y 5a) al truncarse este relieve en mayor proporción al norte de Iquique. Yánez y Cembrano (2004) plantean que se desarrolló un mayor acople interplaca en el Neógeno, generando una flexura en la placa Sudamericana. Este acoplamiento fue mayor entre los $18^{\circ}-20^{\circ} \mathrm{S}$, es decir, entre Arica e Iquique de tal modo que esta flexura debió ser mayor en esta zona, generando mayor subsidencia litoral y provocando un mayor retroceso al este del talud del Acantilado Costero. Esta flexura de la placa Sudamericana explica además la existencia de subsidencia litoral y alzamiento en la Precordillera.

\subsection{Alzamiento litoral local}

El alzamiento litoral local está dominado por la actividad de las fallas inversas de rumbo E-O, ya que afectan la plataforma de abrasión marina emergida con posterioridad a los $2 \mathrm{Ma}$. Las fallas presentes entre la desembocadura de la quebrada Camarones y Pisagua afectaron la terraza marina pleistocena asociada al interglacial que ocurrió a los 126 ka (Casanova, 2005), indicando una actividad pleistocena tardía para estas fallas. Carrizo et al. (2008b) señalan que algunas de estas fallas tienen actividad sísmica actual. La plataforma de abrasión marina también se encuentra afectada por la presencia de fallas inversas de rumbo E-O en el sector de Barranco Alto (entre Iquique y Patilllos) (Allmendinger et al., 2005) y en las cercanías de la desembocadura del río Loa (Figs. 1 y 4) donde la propagación en profundidad de estas fallas forman superficies antiformes en la plataforma de abrasión marina emergida, y el consecuente alzamiento local contribuye al ancho y altura mayores que presenta esta plataforma en estas zonas. La actividad de estas fallas inversas ha sido explicada debido a la presencia de un oroclinal en los Andes Centrales sea en el eje de simetría de Ghepart aproximadamente a los 21, $7^{\circ} \mathrm{S}$ (Allmendinger et al., 2005), o en la latitud de Arica, $18,5^{\circ} \mathrm{S}$ (Carrizo et al., 2008b). En este último caso, los autores indican además que la partición de la subducción oblicua genera un 'sliver' (bloque entre la fosa y arco magmático) en el antearco que se mueve al norte existiendo una barrera en su movimiento al norte de Arica debido al cambio de orientación de la Cordillera de los Andes, generándose compresión N-S en la Cordillera de la Costa.

El alzamiento generado por la actividad de estas fallas se opone a la subsidencia cosísmica litoral entre la desembocadura de la quebrada Camarones y Pisagua emergiendo localmente la plataforma de abrasión marina configurando un Acantilado Costero inactivo; y se adiciona al alzamiento cosísmico regional al sur de Iquique, hasta la desembocadura del río Loa donde se presenta la falla más austral de este sistema de fallas. Estas fallas fueron activas durante el período de subsidencia litoral en el norte de Chile que originó el Acantilado Costero con anterioridad a los 2 Ma (Allmendinger et al., 2005), así como durante el Pleistoceno y algunas incluso presentan actividad sísmica actual (Carrizo et al., 2008b).

Las fallas del SFA no contribuyen al alzamiento pleistoceno del litoral del norte de Chile, por lo menos en los segmentos Paposo y Salado, ya que no existe desplazamiento diferencial en la plataforma de abrasión marina emergida que es atravesada por las trazas de fallas asociadas a estos segmentos al sur de Paposo y Taltal respectivamente, aunque es posible que exista una pequeña contribución del alzamiento litoral en el segmento Salar del Carmen, ya que esta falla ha presentado actividad pleistocena (González et al., 2006). La plataforma de abrasión marina no presenta desniveles en las zonas donde es atravesada por las fallas del sistema NNO-SSE por lo que éstas no influyen tampoco en el alzamiento litoral local. 


\subsection{Evolución del relieve}

La evolución del relieve del borde costero del norte de Chile puede atribuirse al modelo de Davis, con un proceso inicial que generó la topografía, como un alzamiento pre Neógeno de la Cordillera de la Costa que conforma la topografía antigua de este relieve y una subsidencia miocena-pliocena que originó el talud del Acantilado Costero debido al fortalecimiento de la abrasión marina, erosionando la topografía antigua de la Cordillera de la Costa. El alzamiento posterior que aisló este efecto significó que el talud del Acantilado Costero quedó expuesto a los procesos subaéreos ligados al clima, pero debido a la hiperaridez del Desierto de Atacama que provoca bajas tasas de erosión, se produce una extraordinaria preservación del talud del Acantilado Costero desde que el litoral comienza a emerger. Esto es válido también si existiera un cambio en la tectónica (regional o local) y los segmentos activos actuales del Acantilado Costero comienzan a emerger.

\section{Conclusiones}

Las características del relieve indican un incremento hacia el sur de la intensidad de degradación del relieve del borde costero del norte de Chile, la que a su vez es función de los siguientes tres factores: la litología, el clima y la altura respecto del nivel de base. En este caso se puede considerar que el factor litológico es relativamente constante a lo largo de la Cordillera de la Costa. De este modo, el factor climático resulta ser el factor más significativo que puede estar controlando las características morfológicas contrastantes entre los extremos norte y sur del área de estudio. En efecto, la distribución de las precipitaciones a lo largo de la Cordillera de la Costa varía en un orden de magnitud entre el extremo norte y sur del área de estudio $(0,6 \mathrm{~mm} /$ año en Iquique y $12 \mathrm{~mm} / \mathrm{año}$ en Chañaral). Con estos antecedentes es posible sugerir que la configuración morfológica de la vertiente occidental de la Cordillera de la Costa refleja una estabilidad climática al menos para los últimos $2 \mathrm{Ma}$, que ha estado marcada por la hiperaridez en toda el área de estudio, pero que disminuye hacia el sur. El límite actual entre una zona de hiperaridez extrema y otra de condiciones hiperáridas menos marcadas ocurre aproximadamente a los $26^{\circ} \mathrm{S}$.

Los índices morfométricos indican que al norte de $\operatorname{los} 22^{\circ} \mathrm{S}$ el relieve se encuentra extraordinariamente preservado y al sur de los $26^{\circ} \mathrm{S}$ se encuentra muy erosionado, esto último coincide con un aumento de las precipitaciones en un orden de magnitud, superando los $10 \mathrm{~mm} / \mathrm{a}$. No obstante, estos índices sugieren que la transición entre la topografía menos erosionada en el extremo norte y más erosionada en el sur se ubica entre los $22^{\circ}$ a $24^{\circ} \mathrm{S}$, segmento que posee una pluviosidad similar. Esto indica que las variaciones en el grado de erosión no están exactamente acopladas con el cambio en la tasa de precipitaciones. Una explicación para ello es que el límite geográfico entre precipitaciones menores a $10 \mathrm{~mm} /$ año y mayores a $10 \mathrm{~mm} /$ año ha presentado variaciones latitudinales temporales a una escala de tiempo que no se puede definir con los antecedentes actuales. Otra explicación del no acople de la erosión de la topografía de la Cordillera de la Costa y las precipitaciones, es el efecto de la topografía de la Cordillera de la Costa que es truncada por el Acantilado Costero. Esta topografía, constituida por un paleorrelieve pre Neógeno que ha sido desnivelado por la actividad de fallas del SFA, fallas inversas E-O y fallas del sistema NNO-SSE, configura cuencas hidrográficas de superficies variables para los drenajes que descienden por el Acantilado Costero con diferente potencial erosivo. Esta topografía truncada controla además la altura del Acantilado Costero y, en consecuencia, la energía potencial de los drenajes, lo cual influye en la erosión del talud.

Si se analiza la relación entre las tasas de erosión y las tasas de levantamiento del litoral durante el Pleistoceno, se puede inferir que las tasas de erosión son uno o dos órdenes de magnitud más bajas que las tasas de alzamiento. Ello permite inferir que la existencia y preservación del Acantilado Costero en el norte de Chile, resulta de un desbalance entre la intensidad y velocidad de los procesos tectónicos y erosivos. Con esto se puede postular que el Acantilado Costero, más que un rasgo tectónico, es un marcador climático de primer orden de la hiperaridez del Desierto de Atacama.

\section{Agradecimientos}

Este trabajo fue posible de realizar gracias al aporte de los proyectos 'Interacción entre procesos endógenos y exógenos en la configuración del relieve costero del norte de Chile', de la Dirección General de Investigación y Cooperación Técnica de la Universidad Católica del Norte, y 'Fortalecimiento de la investigación y la docencia de postgrado en el Departamento de Ciencias Geológicas de 
la Universidad Católica del Norte: Creación del Laboratorio de Tectónica aplicada' de la Fundación Andes. Se agradece el enorme esfuerzo y trabajo del Dr. G. González y Dr. R. Riquelme de la Universidad Católica del Norte del programa de Doctorado en Ciencias, mención Geología, que contribuyeron significativamente a la elaboración del presente texto. La revisión y recomendaciones del texto original de la presente contribución por parte del Dr. J. Skármeta, Dr. C. Costa y especialmente el Dr. J. Cembrano, contribuyeron significativamente en su mejora. Del mismo modo, las observaciones de una versión anterior del texto por parte del Dr. G. Hérail del IRD y H. Niemeyer de la Universidad Católica del Norte fueron muy importantes. A todos ellos nuestros agradecimientos sinceros. Las interpretaciones y especulaciones planteadas en el presente trabajo son de exclusiva responsabilidad de los autores.

\section{Referencias}

Achurra, L. 2004. Cambios del nivel del mar y evolución tectónica de la cuenca neógena de Caldera, III Región. Memoria de Título (Inédito), Universidad de Chile, Departamento de Geología: 138 p.

Allmendiger, R.; González, G.; Yu, J.; Hoke, G.; Isacks, B. 2005. Trench-Parallel Shortening in the Northern Chilean Forearc: Tectonic and climatic implications. Geological Society of America Bulletin 117 (1-2): 89-104, doi: 10.1130/B25505.1.

Alpers, C.; Brimhall, G. 1988. Middle Miocene climatic change in the Atacama Desert, northern Chile: Evidence from supergene mineralization at La Escondida. Geological Society of America Bulletin 100: 1640-1656.

Arabasz, W. 1971. Geological and geophysical studies of the Atacama fault zone in Northern Chile. Ph.D. Thesis (Unpublished), California Institute of Technology, Pasadena. CA.: 264 p.

Armijo, R.; Thiele, R. 1990. Active Faulting in northern Chile: ramp stacking and lateral decoupling along a subduction plate boundary. Earth and Planetary Science Letters 98: 90-61.

Béjar-Pizarro, M.; Carrizo, D.; Socquet, A.; Armijo, R.; Ruegg, J.; de Chabalier, J.; Nercessian, A.; Charade, O.; Bonvalot, S. 2008. The November 14, 2007, $\mathrm{Mw}=7.7$ Tocopilla (Chile) earthquake: Preliminary results from InSAR and GPS. In International Symposium on Andean Geodynamics, No. 7, Actas: 77-80. Niza, Francia.

Bonnet, S. 1996. Le socle Armonicain au Pléistocéne. Ph.D. Thesis (Unpublished), Université de Rennes I: 352 p.
Brüggen, J. 1950. Fundamentos de la Geología de Chile. Instituto Geográfico Militar: 374 p. Santiago.

Burbank, D.; Anderson, R. 2001. Tectonic Geomorphology. Blackwell Science: 273 p. Massachusetts.

Bull, W.; Mc Fadden, L. 1977. Tectonic geomorphology north and south of the Garlock fault, California. In Geomorphology in arid regions (Dohering, D.; editor). Annual Geomorphology Symposia Series, No. 8: 115-136. Binghampton.

Carrizo, D.; González, G.; Dunai, T. 2008a. Constricción neógena en la Cordillera de la Costa, norte de Chile: neotectónica y datación de superficies con ${ }^{21} \mathrm{Ne}$ cosmogónico. Revista Geológica de Chile 35 (1): 1-38.

Carrizo, D.; González, G.; Dunai, T. 2008b. Long-lived constrictional strain field of the inner part of the Andean Orocline: An example of buttressing effect in oblique subduction curved margin. In International Symposium on Andean Geodynamics, No. 7, Actas: 113-115. Niza, Francia.

Casanova, C. 2005. Desarrollo de plataformas costeras en la vertiente occidental de la Cordillera de la Costa en la Región de Tarapacá, norte de Chile (19² $\left.15^{\prime}-19^{\circ} 40^{\prime} \mathrm{S}\right)$. Memoria para optar al título de Geólogo (Inédito), Universidad Católica del Norte, Departamento de Ciencias Geológicas: 94 p.

Cecioni, G.; García, F. 1960. Observaciones geológicas en la Cordillera de la Costa de Tarapacá. Instituto de Investigaciones Geológicas, Boletín 6: 28 p.

Cembrano, J.; González, G.; Arancibia, G.; Ahumada, I.; Olivares, V.; Herrera, V. 2005. Fault zone development and strain partitioning in an extensional strike-slip duplex: A case study from the Mesozoic Atacama fault system. Tectonophysics 400: 105-125.

Clift, P.; Hartley, A. 2007. Slow rates of subduction erosion and coastal underplating along the Andean margin of Chile and Peru. Geology 35 (6): 503-506.

Davis, W. 1899. The geographical cycle. Geographycal Journal 14: 481-504.

Delouis, B.; Philip, H.; Dorbath, L.; Cisternas, A. 1998. Recent crustal deformation in the Antofagasta region (northern Chile) and the subduction process. Geophysical Journal Internacional 132: 302-338.

Dirección Meteorológica de Chile. 2005. Climas de Chile. Dirección Meteorológica de Chile. Dirección General de Aeronáutica Civil. www.meteochile.cl.

Dunai, T.; González, G.; Juez, J. 2005. Oligocene-Miocene age of aridity in the Atacama Desert revealed by exposure dating of erosion-sensitice landforms. Geology 33: 321-324.

Farías, M.; Charrier, R.; Comte, D.; Martinod, J.; Hérail, 
G. 2005. Late Cenozoic deformation and uplift of the western flank of the Altiplano: Evidence from the depositional, tectonic, and geomorphologic evolution and shallow seismic activity (northern Chile at $19^{\circ} 30^{\prime} \mathrm{S}$ ). Tectonics 24, TC4001 doi:10.1029/2004TC001667.

García, F. 1967. Geología del Norte Grande de Chile. Sociedad Geológica de Chile, Publicaciones: 138 p. Santiago.

Godoy, E.; Marquardt, C.; Blanco, N. 2003. Carta Caldera. Región de Atacama. Servicio Nacional de Geología y Minería, Carta Geológica de Chile, Serie Geología Básica 76: $38 \mathrm{p}$.

González, G.; Cembrano, J.; Carrizo, D.; Macci, A.; Schneider, H. 2003. The link between forearc tectonics and Pliocene-Quaternary deformation of the Coastal Cordillera, northern Chile. Journal of South American Earth Sciences 16: 321-342.

González, G.; Dunai, T.; Carrizo, D.; Allmendinger, R. 2006. Young displacements on the Atacama Fault System, northern Chile from field observations and cosmogenic ${ }^{21} \mathrm{Ne}$ concentrations. Tectonics 25: TC3006, doi:10.1029/2005TC001846.

Hack, J. 1975. Dynamic equilibrium and landscape evolution. In Theories of landform Evolution (Melhorn, W.N.; Flemal, R.C.; editors). Allen and Unwin: 87-102. Boston.

Hartley, A. 2003. Andean uplift and climate change. Journal of the Geological Society of London 160: 7-10.

Hartley, A.; Jolley, E. 1995. Tectonic Implications of Late Cenozoic sedimentation from the Coastal Cordillera of northern Chile $\left(22-24^{\circ} \mathrm{S}\right)$. Journal of the Geological Society of London 152: 51-63.

Hartley, A.; Chong, G. 2002. Late Pliocene age for the Atacama Desert: Implications for the desertification of western South America. Geology 30 (1): 43-46.

Hartley, A.; Chong, G.; Houston, J.; Mather, E. 2005. 150 million years of climatic stability: evidence from the Atacama Desert, northern Chile. Journal of the Geological Society of London 162: 421-424.

Hervé, M. 1987. Movimiento Normal de la Falla Paposo, Zona de Falla de Atacama, en el Mioceno, Chile. Revista Geológica de Chile 31: 31-36.

Houston, J.; Hartley, A. 2003. The central Andean westslope rainshadow and its potential contribution to the origin of hyper-aridity in the Atacama Desert. International Journal of Climatology 23: 1453-1464.

Kausel, E. 1986. Los terremotos de agosto de 1868 y mayo de 1877 que afectaron el sur del Perú y norte de Chile. Boletín de la Academia Chilena de Ciencias 3: 8-14.

Keller, E.; Pinter, N. 1996. Active tectonics: Earthquakes, Uplift and Landscape. Prentice Hall: 338 p. New Jersey.

Klotz, J.; Angermann, G.; Michel, W.; Porth, R.; Reigber,
C.; Reinking, J.; Viramonte, J.; Perdomo, R.; Ríos, H.; Barrientos, S.; Barriga, R.; Cifuentes, O. 1999. GPS derived deformation of the central Andes including the 1995 Antofagasta Mw=8,0 Earthquake. Pure and Applied Geophysics 154: 709-730.

Kober, F.; Schlunegger, F.; Wieler, R.; Ivi-Ochs, S.; Simpson, G. 2002. Determination of erotion rates in a decoupled river and pediplane system in the Central Andes, northern Chile. In International Symposium on Andean Geodynamics, No. 5, Actas: 347-349. Toulouse, Francia.

Leonard, E.; Wehmiller, J. 1991. Geochronology of marine terraces at Caleta Michilla, northern Chile: implications for the Late Pleistocene and Holocene uplift. Revista Geológica de Chile 18: 81-86.

Le Roux, J.; Gómez, C.; Venegas, C.; Fenner, J.; Middleton, H.; Marchant, M.; Buchbinder, B.; Frassinetti, D.; Marquardt, C.; Gregory-Wodzicki, K.; Lavenu, A. 2005a. Neogene-Quaternary coastal and offshore sedimentation in north central Chile: Record of sealevel changes and implications for Andean tectonism. Journal of South American Earth Sciences 19: 83-98.

Le Roux, J.; Gómez, C.; Olivares, D.; Middleton, H. 2005b. Determining the neogene behaviour of the Nazca Plate by geohistory analysis. Geology 33 (3): 165-168.

Marquardt, C.; Lavenu, A.; Ortlieb, L.; Godoy, E.; Comte, C. 2004. Coastal neotectonics in Southern Central Andes: uplift and deformation of marine terraces in Northern Chile (27º $)$. Tectonophysics 394: 193-219.

Marquardt, C.; Fornari, M.; Lavenu, A.; Vargas, G.; Ortlieb, L.; Fritz, J.; Philip, H.; Marinovic, N. 2005. Volcanic ash dating from the Mejillones Peninsula $\left(23^{\circ} \mathrm{S}\right)$ : Implications for the Neogene outer fore-arc stratigraphy, tectonics and volcanic relationships. In International Symposium on Andean Geodynamics, No. 6, Actas: 477-480. Barcelona, España.

Martínez, E.; Niemeyer, H. 1982. Depósitos marinos aterrazados del Plioceno superior en la ciudad de Antofagasta, su relación con la Falla de Atacama. In Congreso Geológico Chileno, No. 3, Actas 1: A176A188. Concepción.

Molnar, P.; England, P. 1990. Late Cenozoic uplift of mountain ranges and global climate change, chicken or egg? Nature 346: 29-34.

Mortimer, C. 1973. The Cenozoic history of the southern Atacama Desert, Chile. Geological Society of London Journal 129: 505-526.

Mortimer, C. 1980. Drainaje evolution in the Atacama desert of Northern Chile. Revista Geológica de Chile 11: 3-28. 
Mortimer, C.; Saric, N. 1972. Landform Evolution in the Coastal Region Tarapaca Province, Chile. Geomorphologie Dynamique 21: 162-170.

Mortimer, C.; Saric, N. 1975. Cenozoic studies in northernmost Chile. Geologishe Rundschau 64 (2): 395-420.

Mortimer, C.; Farrar, E.; Saric, N.; 1974. K-Ar ages from Tertiary lavas of the northernmost Chilean Andes. Geologishe Rundschau 63: 395-420.

Naranjo, J.; Paskoff, R. 1985. Evolución cenozoica del piedemonte andino en la Pampa del Tamarugal, norte de Chile ( $\left.18^{\circ}-21^{\circ} \mathrm{S}\right)$. In Congreso Geológico Chileno, No. 4, Actas 5: 149-164. Antofagasta.

Niemeyer, H.; De los Ríos, E.; González, G. 1996. Evolución tectónica cenozoica del margen continental activo de Antofagasta, norte de Chile. Revista Geológica de Chile 23 (2): 165-186.

Ohmori, H. 1993. Changes in the hypsometric curve through mountain building resulting from concurrent tectonics and denudation. Geomorphology 8: 263-277.

Okada, A. 1971. On the neotectonics of the Atacama fault zone region. Preliminary notes on late Cenozoic faulting and geomorphic development of the Coast Range of northern Chile. University of Tokyo, Department of Geography Bulletin 3: 47-65.

Ortlieb, L. 1995. Paleoclimas cuaternarios en el norte grande de Chile. In Cambios cuaternarios en América del Sur (Argollo, J.; Mourgiart, Ph.; editors): 225246. La Paz.

Ortlieb, L.; Ghaleb, B.; Goy, J-L.; Zazo, C.; Thiele, R. 1994. Terrazas marinas Pleistocenas del área de Hornitos (II Región): nuevos estudios morfoestratigráficos y geotectónicos en el Norte Grande de Chile. In Congreso Geológico Chileno, No. 7, Actas 1: 356-360. Concepción.

Ortlieb, L.; Zazo, C.; Marcel, J.; Ghaleb, B.; Cournover, L. 1996. Coastal deformation and sea levels changes in the northern Chile subduction area $\left(23^{\circ} \mathrm{S}\right)$ during the last 330 ky. Quaternary Science Reviews 15: 819-831.

Paskoff, R. 1979. Sobre la Evolución Geomorfológica del gran acantilado costero del Norte Grande de Chile. Norte Grande. Universidad Católica de Chile, Instituto de Geografía, 6: 7-22.

Penck, W. 1953. Morphological analysis of landforms. New York St. Martin's Press.: 429 p. Nueva York.

Quezada, J. 2006. Fenómenos climáticos anómalos en el litoral del Norte de Chile y su impacto en el relieve. In Congreso Geológico Chileno, No. 11, Actas 2: 133-136. Antofagasta.

Quezada, J.; Cerda, J. 2003. Incisiones transversales profundas en la Cordillera de la Costa del
Norte grande de Chile: ¿erosión de un alto topográfico al oeste del gran acantilado costero? In Congreso Geológico Chileno, No. 10, Actas, CDRom. Concepción.

Quezada, J.; Bataille, K.; González, G. 2005. The effect of subduction earthquakes in the coastal configuration of northern Chile. In International Symposium on Andean Geodynamics, No. 6, Actas: 578-581. Barcelona, España.

Quezada, J.; González, G.; Dunai, T.; Jensen, A.; Juez, J. 2007. Alzamiento Litoral Pleistoceno del Norte de Chile: edades ${ }^{21} \mathrm{Ne}$ de la Terraza Costera más Alta del Área de Caldera-Bahía Inglesa. Revista Geológica de Chile 34 (1): 81-96.

Riquelme, R.; Martinod, J.; Hérail, G.; Darrozes, J.; Charrier, R. 2003. A geomorphological approach to determining the Neogene to Recent tectonic deformation in the Coastal Cordillera of northern Chile (Atacama). Tectonophysics 361: 255-275.

Riquelme, R.; Hérail, G.; Martinod, J.; Charrier, R.; Darrozes, J. 2007. Late Cenozoic geomorphologic signal of Andean forearc deformation and tilting associated with the uplift and climate changes of the Southern Atacama Desert $\left(26^{\circ} \mathrm{S}-28^{\circ} \mathrm{S}\right)$. Geomorphology 86 : 283-306.

Riquelme, R.; Darrozes, J.; Maire, E.; Hérail, G.; Soula, J. 2008. Long-term denudation rates from the Central Andes (Chile) estimated from a Digital Elevation Model using the Black Top Hat function and Inverse Distance Weighting: implications for the Neogene climate of the Atacama Desert. Revista Geológica de Chile 35 (1): 105-121.

Ruegg, J.; Campos, J.; Armijo, R.; Barrientos, S.; Briote, P.; Thiele, R.; Arancibia, M.; Cañuta, J.; Duquesnoy, T.; Chang, M.; Lazo, D. 1996. The Mw=8,1 Antofagasta Earthquake North Chile of July 30, 1995: First results from teleseismic and geodetic data. Geophysical Research letters 23 (9): 917-920.

Salas, R.; Kast, R.; Montecinos, F.; Salas, I. 1966. Geología y recursos minerales del Departamento de Arica, Provincia de Tarapacá. Instituto de Investigaciones Geológicas, Boletín 21: 130 p.

Scheuber, E.; Andriessen, A. 1990. The kinematics and geodynamic significance of the Atacama fault zone, northern Chile. Journal of Structural Geology 12: 243-237.

Serón, M.; Soto, P.; Meneses, C.; Riquelme, R.; Quezada, J. 2006. Applying data mining to determine relationships between relief and precipitations: a case of study in northern Chile. Research in Computing Science 25: $87-108$. 
Strahler, A. 1952. Dynamic basis of geomorphology. Geological Society of America Bulletin 63: 923-938.

Vargas, G.; Ortlieb, L. 1998. Patrones de variaciones climáticas durante el Cuaternario tardío en la costa de la Región de Antofagasta, Chile. Bulletin de l'Institut Français d'Etudes Andines 27 (3): 385-394.

Vargas, G.; Ortlieb, L.; Rutlant, J. 2000. Aluviones históricos en Antofagasta y su relación con eventos El Niño/Oscilación del Sur. Revista Geológica de Chile 27 (2): 157-176.

Vargas, G.; Pantoja, S.; Rutlant, J.; Lange, C.; Ortlieb, L. 2007. Enhancement of coastal upwelling and interdecadal ENSO-like variability in the Peru-Chile
Current since late 19th century. Geophysical. Research Letters 34: L13607, doi:10.1029/2006GL028812.

Willgoose, G. 1994. A statistic for testing the elevation characteristics of landscape simulation models. Journal of Geophysical Research 99: 13987-13996.

Wörner, G.; Uhlig, D.; Kohler, I.; Seyfried, H. 2002. Evolution of the West Andean Escarpment at $18^{\circ} \mathrm{S}$ (N. Chile) during the last $25 \mathrm{Ma}$ : uplift, erosion and collapse through time. Tectonophysics 345: 183-198.

Yáñez, G.; Cembrano, J. 2004. Role of viscous plate coupling in the late Tertiary Andean tectonics. Journal of Geophysical Research 109: B02407, doi: 10.1029/2003JB002494.

$\overline{\text { Manuscrito recibido: diciembre 3, 2008; revisado/aceptado: agosto 24, } 2009 .}$ 